$\underline{\text { Full length article }}$

\title{
Laser-based Powder Bed Fusion Additive Manufacturing of Pure Copper
}

Suraj Dinkar Jadhav a, 1, *, Louca Goossens ${ }^{\text {b, }}{ }^{\text {, }}$, Yannis Kinds ${ }^{\text {b }}$, Brecht Van Hooreweder ${ }^{\text {b, }}$, and Kim Vanmeensel ${ }^{\text {a, } 2}$

${ }^{a}$ KU Leuven, Department of Materials Engineering, Kasteelpark Arenberg 44, B-3001 Heverlee, Belgium

${ }^{\mathrm{b}}$ KU Leuven, Department of Mechanical Engineering \& Member of Flanders Make, Celestijnenlaan 300, B-3001 Heverlee, Belgium

1: Joint first authors,

2: Joint senior authors,

*Corresponding author: E-mail address: suraj.jadhav@kuleuven.be

Keywords: Additive manufacturing; Selective laser melting; Laser-based powder bed fusion; Infrared fiber laser; Copper reflectivity

\begin{abstract}
In this article, the laser-based powder bed fusion (L-PBF) processing behavior of pure copper powder is evaluated by employing a conventional infrared fiber laser with a wavelength of $1080 \mathrm{~nm}$, a small focal spot diameter of $37.5 \mu \mathrm{m}$, and power levels up to $500 \mathrm{~W}$. It is shown that bulk solid copper parts with near full density ( $\rho$ Archimedes $=99.3 \pm 0.2 \%, \rho$ Optical $=99.8 \pm 0.1 \%$ ) can be produced using a laser power of $500 \mathrm{~W}$ for the chosen combination of powder particle size, L-PBF settings, and pure copper baseplate. Moreover, at $500 \mathrm{~W}$, parts with a relative density exceeding $99 \%$ are manufactured within a volumetric energy density window of $230-310 \mathrm{~J} / \mathrm{mm}^{3}$, while laser power levels below $500 \mathrm{~W}$ did not produce parts with a relative density above $99 \%$. An analytical model is used to elucidate the L-PBF processing behavior, wherein both conduction and keyhole regimes corresponding to the employed L-PBF settings are identified. The analytical model-based results predict that the bulk solid copper parts with near full density are produced in a keyhole regime prior to the onset of keyholeinduced porosity, which is in accordance with the porosity types observed in the parts. The L-PBF fabricated copper parts exhibit an electrical conductivity of $94 \pm 1 \%$ compared to the international annealed copper standard (IACS) and demonstrate a tensile strength of $211 \pm 4 \mathrm{MPa}$, a yield strength of $122 \pm 1 \mathrm{MPa}$, and an elongation at break of $43 \pm 3 \%$ in the as-built condition.
\end{abstract}




\section{Introduction}

The performance of electrical or thermal management components is assessed based on their ability to transfer electric-current or heat while maintaining the service temperature and keeping the electrical or thermal losses at the minimum level, respectively. Consequently, the performance improvement of electrical and thermal management components is largely dependent on the physical properties of the material, such as electrical and thermal conductivity of copper, as well as the geometrical design. In the past, a significant improvement in the electrical and heat transfer performance utilizing both the aforementioned aspects has been achieved. However, further improvements have been decelerated due to the natural limitation imposed by the physical property of the conducting material (e.g., copper) and the limited geometrical freedom offered by conventional manufacturing processes $[1,2]$. Logically, researchers are currently focusing on the latter aspect, wherein the use of new additive manufacturing (AM) technologies, such as binder jetting (BJT), electron beam melting (EBM), and laser-based powder bed fusion (L-PBF), is being evaluated. A detailed review on the use of various AM techniques for manufacturing of copper and copper alloy components is given in [3]. Among all research directions, the combination of low-cost, readily available, corrosion-resistant, and highly conductive pure copper as the material and laser-based powder bed fusion (L-PBF) as the manufacturing process is attracting a lot of interest by academic and industrial research, which aims to satisfy the growing demand on the efficiency of electrical and thermal management components [4]. This research interest is fueled by the layer-by-layer fabrication nature and the digital process chain of the L-PBF process, which allows the fabrication of complex-shaped customized parts exhibiting significantly improved surface area to volume ratios in shorter lead times, unlike the conventional manufacturing processes [5].

L-PBF is a powder-bed-based AM technique, utilizing a high power laser energy source to melt and solidify successive layers of powder, to form a 3-D part [6]. The L-PBF technique has allowed the fabrication of geometrically complex-shaped components made of a wide range of optically absorptive and low thermally conductive metals and alloys [7]. However, the fabrication of such geometrically complex-shaped components made of high optically reflective and thermally conductive metals and alloys, such as copper and copper alloys, via L-PBF is still being evaluated [2]. As a part of such research exploration, feasibility studies for the manufacturing of crack-free and dense copper components via L-PBF have been performed by Lykov et al. [8], Benedetti et al. [9], Trevisan et al. [10], and Silbernagel et al. [11] using infrared fiber $(\lambda \approx 1064 \mathrm{~nm})$ or $\mathrm{CO}_{2}(\lambda \approx 10600 \mathrm{~nm})$ lasers with output power levels below $200 \mathrm{~W}$. The authors revealed that none of the employed L-PBF settings guaranteed the fabrication of dense copper parts without porosities. As such, the as-built parts contain unmolten powder particles along with 'lack of fusion' defects, resulting in relative part density values below $90 \%$. The authors attributed this processing behavior to the combined effect of the high reflectivity of copper in the infrared region (e.g., infrared fiber laser wavelength $(\lambda) \approx 1064 \mathrm{~nm}$ ) and the high thermal conductivity of copper, inhibiting the complete and successful melting of individual powder particles located in the laser-material interaction zone. To enhance the fusion behavior of copper powder particles and the concomitant part density, Sinico et al. [12] used a combination of a finer PSD of $10-35 \mu \mathrm{m}$ and a finer laser focal spot diameter of $30 \mu \mathrm{m}$ at a laser power $(P)$ of $200 \mathrm{~W}$, while Constantin et al. [13] employed a $400 \mathrm{~W}$ infrared fiber laser with a focal spot diameter of $70 \mu \mathrm{m}$. Both of these approaches significantly improved the densification behavior; however, they showed that the production of bulk solid copper components with near full density (> 99\%) was not possible with the use of an infrared fiber laser having a maximum power output below or equal to that of $400 \mathrm{~W}$ for the chosen range of L-PBF settings. Consequently, Ikeshoji et al. [14] employed a significantly higher volumetric energy density by increasing the laser power output to $800 \mathrm{~W}$ and limiting the scan speed (v) to $300 \mathrm{~mm} / \mathrm{s}$, yielding a maximum density of $96.6 \%$, whereas Colopi et al. [15] combined high volumetric energy density with laser powers ranging between 600 and $800 \mathrm{~W}$ with a remelting strategy 
and a low thermal conductivity 316L stainless steel baseplate to manufacture near $99 \%$ dense components. Although these results have shown that nearly dense copper parts can be produced using L-PBF, Jadhav et al. [16] reported optical mirror damage due to laser back-reflections in the L-PBF machine when the output laser power levels between $600-800 \mathrm{~W}$ were used. To minimize or prevent the damage caused by copper back-reflections, the authors [16] suggested to: (1) Use a lower laser power ( $\leq 500 \mathrm{~W}$ combined with a fine laser focal spot diameter), and (2) Avoid the occurrence of copper back-reflection focal point on the optical mirrors via reconfiguration of the optical setup. On the other hand, Naeem [17] proposed diverging copper back-reflections away from the delivery fiber into the optical damper as an option to minimize risks associated with copper back-reflections. Hence, as per the current state-of-the-art, the L-PBF processing behavior of pure copper powder on pure copper baseplate using a focused beam infrared fiber laser with power above $400 \mathrm{~W}$ and below $600 \mathrm{~W}$ is not yet evaluated, which is crucial for the understanding of the densification behavior. Moreover, the melt pool analysis, electrical, thermal, and mechanical properties of the as-built bulk solid copper components with full density have not yet been reported or elucidated.

Accordingly, this work describes the densification behavior of pure copper components produced via the L-PBF process by employing a conventional infrared fiber laser with a wavelength of $1080 \mathrm{~nm}$ and a $1 / \mathrm{e}^{2}$ focal spot diameter of $37.5 \mu \mathrm{m}$. The employed L-PBF settings range between 200 and $500 \mathrm{~W}$ for the laser power and 100 to $1000 \mathrm{~mm} / \mathrm{s}$ for the laser scan speed. The resulting melt pool shapes and their stabilities are studied, and the regions corresponding to the 'lack of fusion' and keyhole porosity are identified experimentally as well as via an analytical model. Consequently, by employing a $500 \mathrm{~W}$ laser power at $800 \mathrm{~mm} / \mathrm{s}$ scan speed, bulk solid copper components exhibiting near full density ( $\rho_{\text {Archimedes }}=99.3 \pm 0.2 \%, \rho$ Optical $=99.8 \pm 0.1 \%$ ) have been produced. Furthermore, the microstructure is analyzed, and the electrical and mechanical properties are evaluated in the as-built condition.

\section{Raw material powder and experimental procedure}

\subsection{Pure copper powder and its characterization}

Pure copper was atomized at Nanoval GmbH \& Co. KG, Germany, using argon gas, starting from oxygen-free high conductivity $99.99 \%$ pure copper pellets supplied by Aurubis Belgium SA/NV. The atomized copper powder exhibiting particle diameter within a $25-60 \mu \mathrm{m}$ range was chosen for the LPBF experiments, and an LS 13320 particle size analyzer of Beckman Coulter ${ }^{\mathrm{TM}}$, which works on the laser diffraction principle, was used to analyze the particle size distribution (PSD). The powder particles exhibited a D10 of $24.6 \mu \mathrm{m}$, D50 of $44.4 \mu \mathrm{m}$, and D90 of $66.8 \mu \mathrm{m}$, as shown in Supplementary Figure 1. The chemical composition of the starting copper powder and L-PBF fabricated parts is indicated in Table 1. The oxygen content was measured using the inert gas fusion technique (EMGA - 820W, Horiba Ltd., Japan), while other elements reported in Table 1 were measured using the inductively coupled plasma - optical emission spectroscopy (iCAPTM 7400 ICP-OES analyzer, Thermo Scientific ${ }^{\text {TM }}$, USA). Both of these techniques allow the determination of chemical elements to ppm-level. As seen, the starting powder and the L-PBF part contain $\approx 100-200$ ppm impurities (including oxygen), and they are believed to be inherited during the gas atomization process, powder handling, and/or the L-PBF process. The visual appearance of the copper powder particles is shown in Figure 1 through images taken using a scanning electron microscope (SEM). As seen, the copper powder contains a mix of particles with varying diameters. The powder particles generally exhibit a spherical shape, and fine satellite powder particles are bonded to the coarser powder particles. A lambda 950 spectrophotometer equipment (PerkinElmer ${ }^{\circledR}$ ) was used to measure the powder optical absorption at room temperature, and a $21 \%$ absorption was recorded at the wavelength $(\lambda)$ of $1080 \mathrm{~nm}$. For the determination of phases present in the starting copper powder and the L-PBF processed part, the XRD spectra were collected within $20-95^{\circ} 2 \theta$ range using a Bruker D2 phaser, Bruker France S.A.S. The Bruker D2 phaser is equipped with a copper $\mathrm{K} \alpha \mathrm{X}$-ray source emitting radiations of $0.15406 \mathrm{~nm}$ wavelength. 
Table 1: Chemical composition [in ppm] of the starting copper powder and the corresponding LPBF fabricated part measured using the inductively coupled plasma - optical emission spectrometry (ICP - OES) technique. The oxygen content was measured using the inert gas fusion technique.

\begin{tabular}{ccccccc}
\hline Sample/Element & $\mathrm{Cr}$ & $\mathrm{Fe}$ & $\mathrm{Ni}$ & $\mathrm{Sn}$ & $\mathrm{O}$ & $\mathrm{Cu}$ \\
\hline Powder & $<10$ & 10 & $<10$ & $<100$ & 115 & Balance \\
\hline Part & $<10$ & 30 & $<10$ & $<100$ & 54 & Balance \\
\hline
\end{tabular}
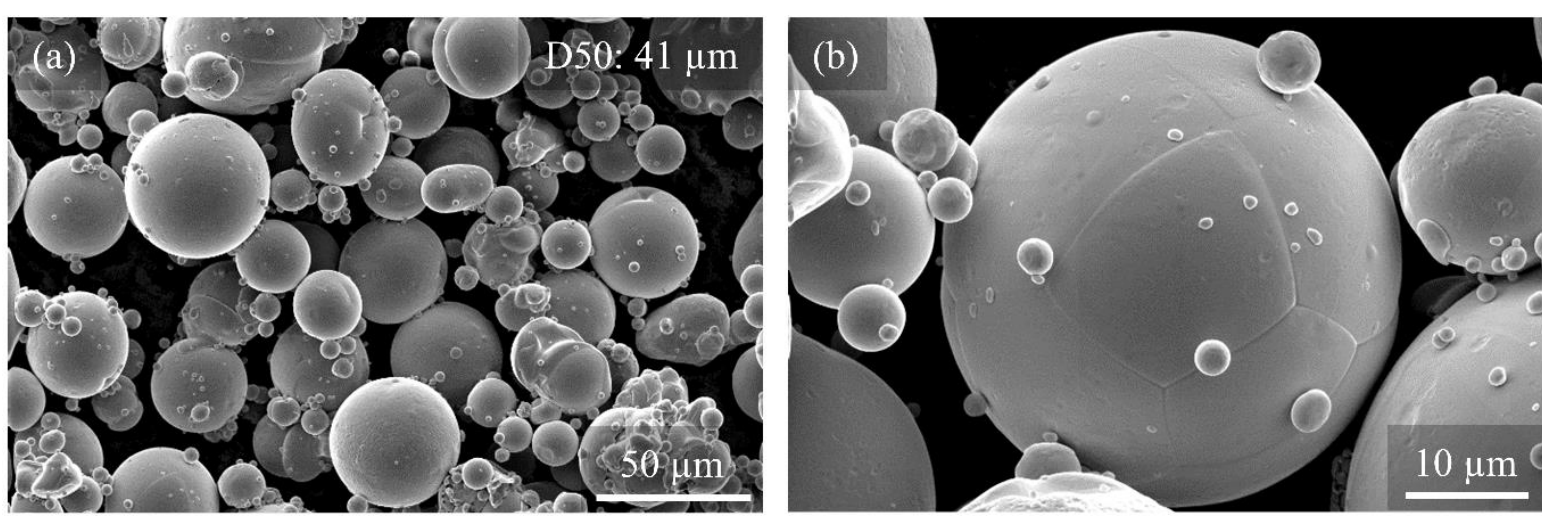

Figure 1: The visual appearance of the copper powder particles at two different magnifications is shown via images taken using a scanning electron microscope (SEM).

\subsection{Laser-based powder bed fusion experimental procedure and characterization of parts}

An in-house built L-PBF machine was used for the fabrication of copper parts [18]. The machine is furnished with an infrared fiber laser exhibiting characteristics, as mentioned in Table 2. Note the word 'infrared fiber laser' used within this research article generally refers to the conventionally used lasers with wavelength $(\lambda)$ in the range of 1060 to $1080 \mathrm{~nm}$. The processability of pure copper powder was evaluated by employing the L-PBF settings, as mentioned in Table 3.

Table 2: Properties of the infrared fiber laser, which is installed on the in-house developed L-PBF machine, used in the current investigation [18]

\begin{tabular}{lll}
\hline Laser property & Value & Symbol, [unit] \\
\hline Maximum output power & 1000 & $\mathrm{P},[\mathrm{W}]$ \\
Focal spot diameter & $0.0375\left(1 / \mathrm{e}^{2}\right.$ value $)$ & $D_{b},[\mathrm{~mm}]$ \\
Wavelength & 1080 & $\lambda,[\mathrm{nm}]$ \\
Output mode & Continuous single-mode & - \\
\hline
\end{tabular}

After fabrication of the parts, a Quintix 224-1S analytical balance of Sartorius AG, Germany, with readability up to $0.1 \mathrm{mg}$ was used to measure their weight in air and ethanol medium. Subsequently, the relative density of parts was calculated using the Archimedes method, considering a reference density of $8.944 \mathrm{~g} / \mathrm{cc}$ for pure copper. The reference (true) density was measured on the starting pure copper powder using a helium gas pycnometery technique (Multipycnometer ${ }^{\mathrm{TM}}$ of Quantachrome Instruments, USA). Generally, the part density values reported within the main text and figures of the manuscript refer to the Archimedes density measurements (unless explicitly mentioned), whereas the part density values corresponding to the optical density measurements are reported in Supplementary Figure 2 (i.e., not included in the main manuscript text). The optical density ( $\rho$ optical) measurements 
were performed on a $5.4 \times 5.4 \mathrm{~mm}^{2}$ area per cross-sectional surface for at least three different crosssectional planes per sample using the ImageJ software program. The melt pools at the top surface of the samples were observed using an SEM (XL30 FEG of Philips, The Nederlands). The cross-sectional surface of $10 \mathrm{~mm} \times 10 \mathrm{~mm}$ per sample was observed in the as-polished (un-etched) condition using a light optical microscope (LOM) of Carl Zeiss NV, Belgium. The microstructure of a 99.3\% dense part (i.e., the part with an optical density ( $\rho$ optical) of $99.8 \%$, refer to Supplementary Figure 2 ) was observed in the as-built condition after etching for $15 \mathrm{~s}$ in a solution made of $3.5 \mathrm{~g}$ of iron (III) chloride, $2.5 \mathrm{~mL}$ of hydrogen chloride, and $75 \mathrm{~mL}$ of ethanol. For all samples, the melt pool widths were measured on the top surface of the samples (which displays the laser scan tracks), while the melt pool depths were measured on the cross-sectional surface of the sample after chemical etching. The measurement methodology of melt pool dimensions is illustrated in Supplementary Figure 3. The micro-Vickers hardness was measured by applying a $0.3 \mathrm{~kg}$ of an indentation load for $15 \mathrm{~s}$ dwell time. The L-PBF settings that offer the production of bulk solid cube-shaped pure copper components with near full density (i.e., laser power $(P)$ of $500 \mathrm{~W}$ and scan speed $(v)$ of $800 \mathrm{~mm} / \mathrm{s}$ ) were used to horizontally build the dog-bone shaped tensile samples and rectangular electrical conductivity bars. Tensile tests were performed on five as-built samples in accordance with the ISO 6892 standard using Instron's tensile testing machine. During the test, the cross-head was moved at a speed of $0.5 \mathrm{~mm} / \mathrm{min}$. An extensometer with a gauge length of $12.5 \mathrm{~mm}$ was used to measure the strain. To determine the conductivity, the electrical resistance of four pure copper parts with dimensions of $(60 \times 5 \times 2) \mathrm{mm}^{3}$ was measured using a four-point contact method perpendicular to the building direction (at three different measuring lengths) on a Resistomat ${ }^{\circledR}$ machine (model 2301-V001 of Burster). Since pure copper obeys the Wiedemann-Franz relationship, thermal conductivity was theoretically calculated from the electrical conductivity measurements. For the thermal conductivity calculations, the Lorenz number (L) of 2.41 $\times 10^{-8}{\mathrm{~W} \Omega \mathrm{K}^{-2}}^{[19]}$ was used.

Table 3: An overview of the L-PBF process settings that are used in the current investigation.

\begin{tabular}{lll}
\hline L-PBF parameters & Employed value(s) & Symbol, [unit] \\
\hline Scan speed & $100,200,400,600,800$, and 1000 & $v,[\mathrm{~mm} / \mathrm{s}]$ \\
Laser power & $200,300,400$, and 500 & $P,[\mathrm{~W}]$ \\
Powder layer thickness & 0.03 & $t,[\mathrm{~mm}]$ \\
Hatch spacing & 0.09 & $h,[\mathrm{~mm}]$ \\
Volumetric energy density & $E=\frac{P}{(v \times h \times t)}$ & $E\left[\mathrm{~J} / \mathrm{mm}^{3}\right]$ \\
Scan strategy within each layer & Zigzag $($ Bi-directional $)$ & - \\
Scan strategy between subsequent layers & $90^{\circ}$ rotation & - \\
L-PBF built chamber atmosphere & Argon & - \\
Base plate material & Pure copper & - \\
Dimensions of optimization samples & $10 \times 10 \times 7$ &,$-\left[\mathrm{mm}^{3}\right]$ \\
Optimized L-PBF process parameter & $P=500 \mathrm{~W}, v=800 \mathrm{~mm} / \mathrm{s}$ & - \\
Density of copper powder & 8.9440 & $\rho_{0},\left[\mathrm{~g} / \mathrm{cm}^{3}\right]$ \\
Software employed for part geometries & Magics, Materialise NV, Belgium & - \\
\hline
\end{tabular}

\subsection{Analytical model for the prediction of conduction and keyhole regimes}

Since the transition between conduction and keyhole mode melting plays a vital role in the processing of reflective metals, such as pure copper, a scaling law-based analytical model introduced by Fabbro et al. [20,21] was utilized for the prediction of melt pool aspect ratios and the corresponding conduction and keyhole mode melting regimes. The model considers all relevant L-PBF processing parameters and thermophysical properties of the material to predict the melt pool depth-to-width ratio 
(hereafter referred to as the melt pool aspect ratio, $R=\frac{e_{m}}{d_{m}}$ ) using Equations (1 - 4) in the keyhole regime. For the full derivation of Equations $(1-4)$, the reader is referred to [21]. The model was constructed with a set of simplifying hypotheses:

(1) The melt pool geometry is approximated by a vertical cylinder with the diameter equal to the laser focal spot size (i.e., $d_{k}=D_{b}$ ) and the length corresponding to the melt pool depth $\left(\mathrm{e}_{\mathrm{m}}\right)$.

(2) The keyhole wall is at a constant temperature $T_{v}$, which is equal to the evaporation temperature of the material.

(3) The melt pool is moving across the substrate (at a temperature $T_{0}$ ) with a laser scan speed $v$.

The thermophysical properties employed for predicting the melt pool aspect ratios were taken at the melting point of pure copper from Mills Kenneth C. [22], and they are listed in Table 4. During the L-PBF process, the baseplate temperature was recorded using a thermocouple (type $\mathrm{K}$ ) mounted near the baseplate-bottom, and a temperature of $\approx 300^{\circ} \mathrm{C}$ was reached at the end of the building process. Consequently, this temperature was chosen as the reference substrate temperature $T_{0}(573 \mathrm{~K})$. In order to predict the threshold between conduction and keyhole mode melting, a condition was set on the predicted melt pool aspect ratio (R). As such, the melting mode is supposed to shift from conduction to keyhole mode melting when an aspect ratio of 1 or higher is achieved. With the laser power and scan speed assumed to be the only varying processing conditions in the current study, the threshold can be put forth as a function of the applied laser power versus scan speed in a typical two-dimensional processing map.

Table 4: Thermophysical properties of pure copper that are employed in the analytical model [22].

\begin{tabular}{lll}
\hline Property & Employed value & Symbol, [unit] \\
\hline Density & 8295 & $\rho,\left[\mathrm{kg} / \mathrm{m}^{3}\right]$ \\
Heat capacity & 469 & $C_{p},[\mathrm{~J} /(\mathrm{kg} \cdot \mathrm{K})]$ \\
Thermal conductivity & 330 & $k,[\mathrm{~W} /(\mathrm{m} \cdot \mathrm{K})]$ \\
Evaporation temperature & 2835 & $T_{v},[\mathrm{~K}]$ \\
Melting temperature & 1357 & $T_{m},[\mathrm{~K}]$ \\
\hline
\end{tabular}

The equations that are used in the analytical model are as follows,

$$
R=\frac{e_{m}}{d_{m}}=\frac{R_{0}}{1+\frac{v}{v_{0}}}
$$

Where,

$$
\begin{aligned}
& R_{0}=\frac{A \times P}{n \times D_{b} \times k \times\left(T_{v}-T_{0}\right)} \\
& v_{0}=\frac{2 \times n \times k}{m \times D_{b} \times \rho \times C_{p}}
\end{aligned}
$$

With,

$R$ - Melt pool aspect ratio (depth-to-width)

$e_{m}$ - Melt pool depth [m]

$d_{m}$ - Melt pool width [m]

$R_{0}$ - Normalized aspect ratio (the aspect ratio at $v=0[\mathrm{~m} / \mathrm{s}]$ )

$v_{0}$ - Characteristic speed at the transition from conduction to convection dominated losses [m/s]

$A$ - Material absorptivity 
$P$ - Laser power $[\mathrm{W}]$

$D_{b}$ - Laser focal spot diameter [m]

$T_{v}$ - Evaporation temperature $[\mathrm{K}]$

$T_{0}$ - Substrate temperature [K]

$k$ - Thermal conductivity $[\mathrm{W} /(\mathrm{m} \cdot \mathrm{K})]$

$v$ - Laser scanning speed $[\mathrm{m} / \mathrm{s}]$

$\mathrm{C}_{\mathrm{p}}$ - Heat capacity $[\mathrm{J} /(\mathrm{kg} \cdot \mathrm{K})]$

$\rho$ - Density $\left[\mathrm{kg} / \mathrm{m}^{3}\right]$

$m$ and $n$ are linear coefficients with values 10 and 1.5, respectively. These coefficients are dependent on the Péclet number $\left(P_{e}\right.$ given by Equation (4)), and the $P_{e}$ number for L-PBF of pure copper with processing parameters presented in Table 3 ranges between 0.03 to 0.3 [20].

$$
P_{e}=\frac{v \times \rho \times C_{p} \times D_{b}}{2 k}
$$

Equation (4)

\section{Results}

\subsection{Experimental findings}

\subsubsection{Laser-based powder bed fusion process optimization}

The L-PBF process optimization was performed by employing a laser scan speed $(v)$ in the range of $100-1000 \mathrm{~mm} / \mathrm{s}$ and laser power $(P)$ in the range of $200-500 \mathrm{~W}$, at the fixed powder layer thickness $(t)$ of $0.03 \mathrm{~mm}$ and hatch spacing $(h)$ of $0.09 \mathrm{~mm}$. Subsequently, a graph of the applied volumetric energy density $(E)$ versus the relative (Archimedes) density of parts is plotted in Figure 2(a). A magnified view of a section of Figure 2(a) is shown in Figure 2(b), and the laser scan speeds corresponding to the laser power of $500 \mathrm{~W}$ are indicated for better clarity. The data points for the relative density of parts are connected using smooth lines for each power level. The linear fit equations, and density values of the corresponding parts measured via an optical method are displayed in Supplementary Figure 2.

In general, a part produced with a higher laser power demonstrates a better density when compared for the same volumetric energy density. However, the previous statement is not valid for the $P 300 \mathrm{~W}$ parts produced within the volumetric energy density range of $500-1150 \mathrm{~J} / \mathrm{mm}^{3}$. A significant improvement in the part density is realized when the employed laser power is changed from 200 to 300 $\mathrm{W}$, while such a huge difference is not observed if the laser power is changed from 300 to $400 \mathrm{~W}$ or from 400 to $500 \mathrm{~W}$. This indicates that the employed laser power has a significant influence on the part density trend and that the applied volumetric energy density cannot solely explain the part density trends, unlike the case for other low thermal conductivity and low reflectivity materials, such as $300 \mathrm{M}$ steel [23] and Ti-6Al-4V [24], where the applied volumetric energy density can tentatively explain the part density trend. Moreover, only the $500 \mathrm{~W}$ laser power allowed the fabrication of a near fully dense ( $\rho_{\text {Archimedes }}=99.3 \pm 0.2 \%, \rho_{\text {Optical }}=99.8 \pm 0.1 \%$ ) copper part, while below $500 \mathrm{~W}$, it did not allow $>99 \%$ density part fabrication. This means that the applied $500 \mathrm{~W}$ laser power was enough for the production of $>99 \%$ copper parts for the chosen combination of powder particle size, L-PBF settings, and pure copper baseplate. Generally, a peak in the relative part density is observed for a very narrow volumetric energy density window, and a slight change in the volumetric energy density (caused by a change in $P$ and/or $v$ ) can have a considerably high influence on the part density. As such, a near fully dense ( $\rho$ Archimedes $=99.3 \pm 0.2 \%, \rho$ Optical $=99.8 \pm 0.1 \%$ ) part is fabricated by applying $P$ of $500 \mathrm{~W}$ and $v$ of 800 $\mathrm{mm} / \mathrm{s}$, whereas the part density drastically decreases to $\approx 93 \%$ if $v$ is changed from 800 to $1000 \mathrm{~mm} / \mathrm{s}$ 
at the same $P$ of $500 \mathrm{~W}$. Similar behavior is also observed for parts processed at 300 and $400 \mathrm{~W}$, when the laser scan speeds are changed from 200 to $400 \mathrm{~mm} / \mathrm{s}$ and from 800 to $1000 \mathrm{~mm} / \mathrm{s}$, respectively. Moreover, as the laser power increases from 300 to $500 \mathrm{~W}$, the peak of the part density curve shifts towards lower volumetric energy density values. This indicates that the laser power followed by laser scan speed have a major influence on the L-PBF processing behavior of pure copper powder within the investigated L-PBF settings.

(a)

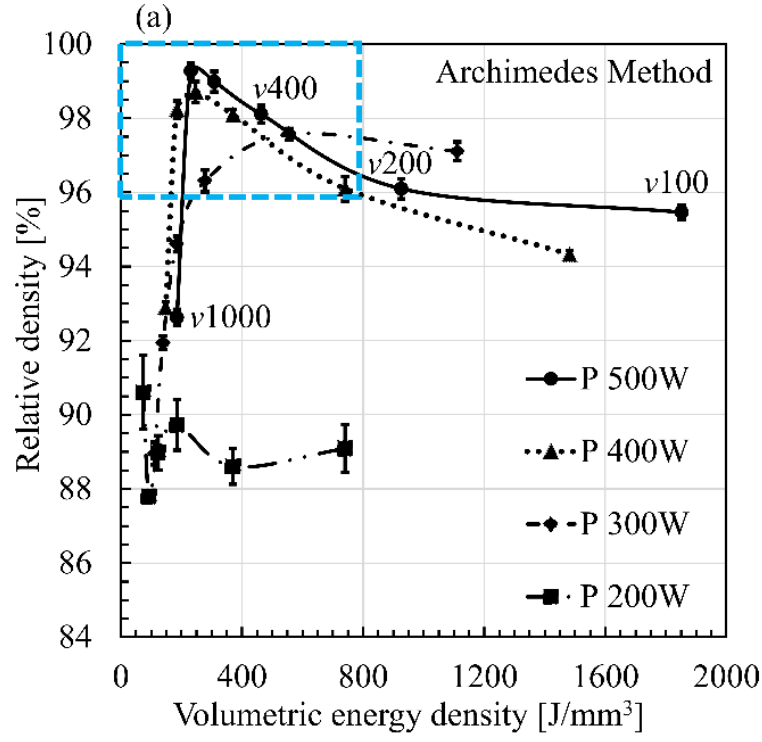

(b)

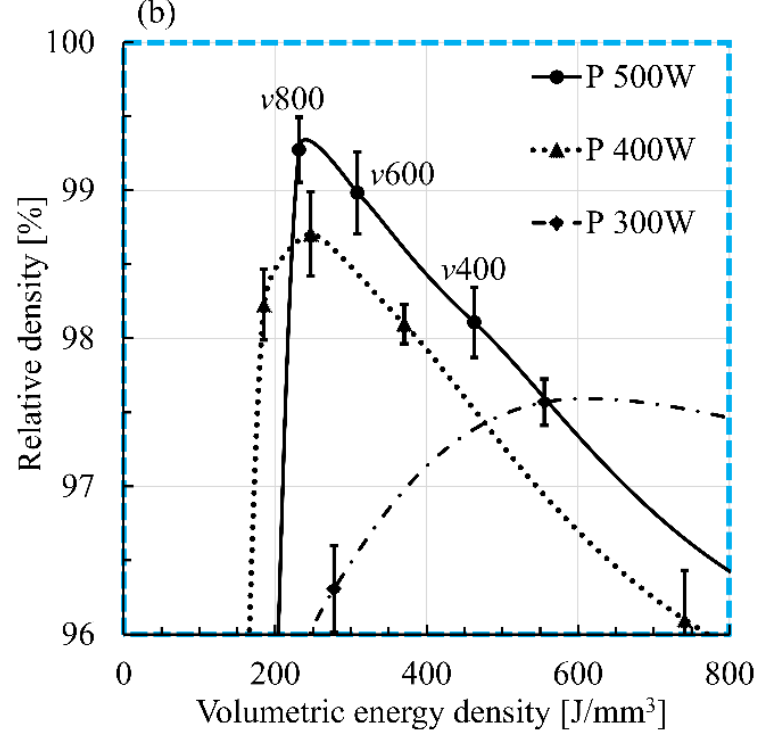

Figure 2: A graph of the relative (Archimedes) density of the fabricated copper samples with different laser power $(P)$ levels in the function of the volumetric energy density $(E)$. A closer view of the graph from Figure (a) is revealed in Figure (b) for better clarity. The error bars indicate the standard deviation between three density measurements, and the laser scan speed $(v)$ values are indicated for the $P 500 \mathrm{~W}$ parts.

\subsubsection{Top surface observations}

Figure 3 shows the top surface of the samples produced by applying various laser power levels $(P)$ of 200, 300, 400, and $500 \mathrm{~W}$ and scan speed $(v)$ levels of 100, 400, 800, and $1000 \mathrm{~mm} / \mathrm{s}$ at the fixed layer thickness $(t)$ of $0.03 \mathrm{~mm}$ and hatch spacing $(h)$ of $0.09 \mathrm{~mm}$. The unmolten powder particles are indicated using dashed red-colored arrows, while porosities are denoted by solid red-colored arrows. The laser scanning directions (SD) are designated using white-colored dashed arrows, and the melt pool shapes are represented by white-colored dashed curves on the top surface of the part that was fabricated employing $P$ of $400 \mathrm{~W}$ and $v$ of $400 \mathrm{~mm} / \mathrm{s}$. The top surface images of the parts that exhibit relative Archimedes density values $>98 \%$ are outlined with green-colored dashed rectangles.

As seen, all parts processed using a $200 \mathrm{~W}$ laser power exhibit unmolten powder particles, porosity, and unstable melt tracks on the top surface, regardless of the employed laser scan speed. This indicates that a $200 \mathrm{~W}$ laser power is not enough to completely fuse the copper powder particles. However, the parts built using $P$ levels of 300 and $400 \mathrm{~W}$ demonstrate rather stable melt tracks when $v$ levels under 400 and $800 \mathrm{~mm} / \mathrm{s}$ are used, respectively. In contrast, the use of $v \geq 400 \mathrm{~mm} / \mathrm{s}$ for $300 \mathrm{~W}$ and $v \geq 800$ $\mathrm{mm} / \mathrm{s}$ for $400 \mathrm{~W}$ disrupted the melt pool stability, and unstable melt tracks are formed. Although some of the parts processed at 300 and $400 \mathrm{~W}$ reveal stable melt tracks, all parts exhibit varying levels of porosity. The $500 \mathrm{~W}$ processed parts display steady-state melt tracks with sufficient overlap between adjoining tracks up to $800 \mathrm{~mm} / \mathrm{s}$ scan speed. However, at $1000 \mathrm{~mm} / \mathrm{s}$, the part processed at $500 \mathrm{~W}$ demonstrates a lot of porosities with unstable melt tracks on the top surface. This indicates that for laser 
power levels of 400 and $500 \mathrm{~W}$, the process stability is compromised when laser scan speeds above 800 $\mathrm{mm} / \mathrm{s}$ and $1000 \mathrm{~mm} / \mathrm{s}$ are used, respectively.

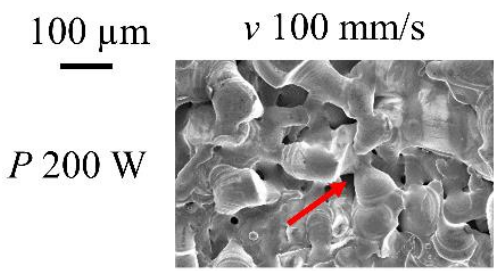

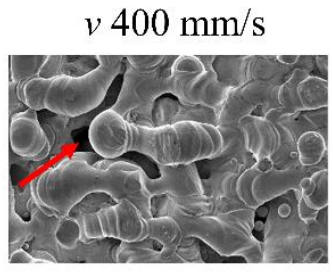

$v 800 \mathrm{~mm} / \mathrm{s}$
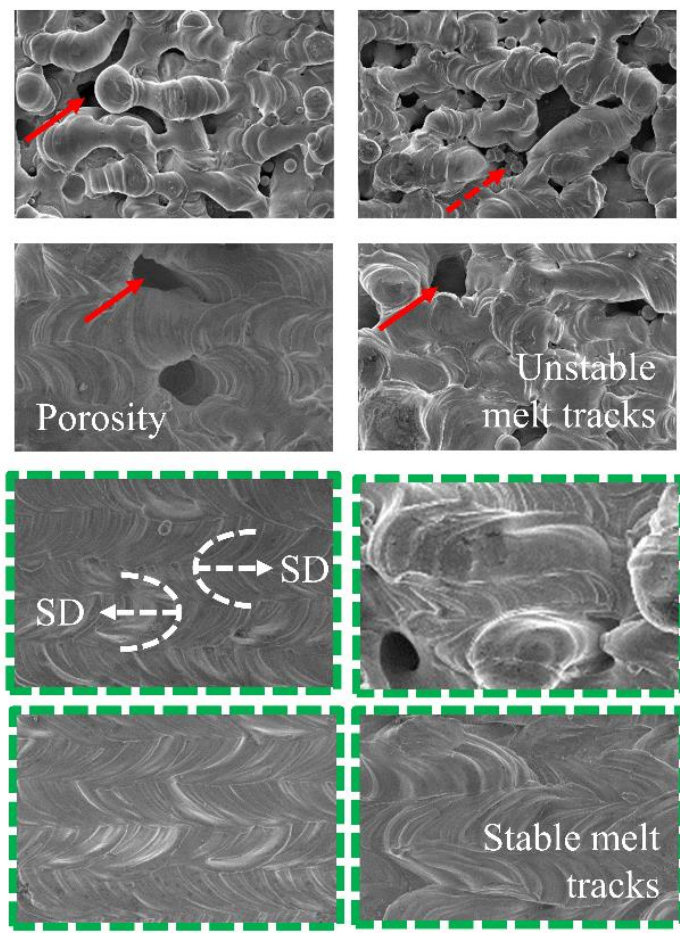
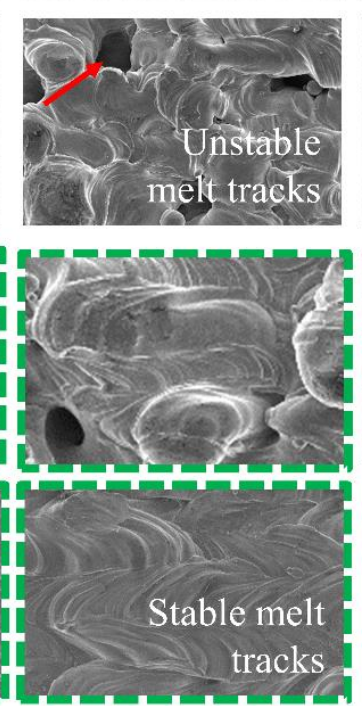

$v 1000 \mathrm{~mm} / \mathrm{s}$
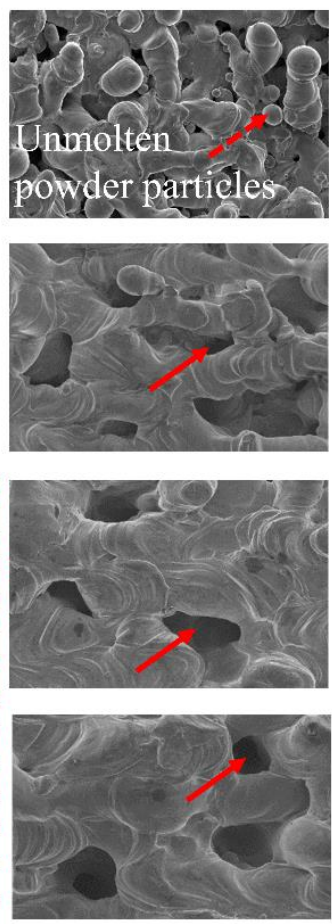

Figure 3: Morphology of melt tracks present on the top surface of the samples built using laser power $(P)$ levels of 200, 300, 400, and $500 \mathrm{~W}$ and laser scan speed $(v)$ levels of 100, 400, 800, and 1000 $\mathrm{mm} / \mathrm{s}$. All parts were built employing a $0.03 \mathrm{~mm}$ powder bed layer thickness and a $0.09 \mathrm{~mm}$ hatch spacing. Note that the scale bar is indicated at the top left corner of the Figure.

\subsubsection{Cross-sectional surface observations}

Figure 4 displays the as-built cross-sectional surface of the samples in the un-etched condition. The top surface of these parts was already shown in Figure 3. The parts exhibiting 'lack of fusion' defects (porosity) are highlighted using a red-colored dashed outline, whereas those with keyhole porosity are grouped using a blue-colored dashed outline. Some parts exhibit both 'lack of fusion' and keyhole porosities as indicated by solid red-colored and dashed blue-colored arrows, respectively, and they are located in the transition region. The relative part density measured by the Archimedes method is displayed on the top right corner of each image, while the melt pool depth-to-width ratio is revealed on the bottom right corner, except for the $200 \mathrm{~W}$ laser power processed parts. The melt pool widths were measured on the top surface, and the melt depths were evaluated within the final non-remelted layer of the chemically etched cross-sectional surface as illustrated in Supplementary Figure 3.

In general, the porosity type and levels observed in Figure 4, matches well with the Archimedes density trend of parts shown in Figure 2 and melt pool morphologies revealed in Figure 3. As such, all parts processed at $200 \mathrm{~W}$ demonstrate poor attachment among subsequent layers caused by the incomplete fusion of copper powder particles. This confirms that a laser power $(P)$ of $200 \mathrm{~W}$ was not enough for melting of the copper powder particles, regardless of the employed laser scan speed $(v)$. Moreover, the $300 \mathrm{~W}$ laser power processed parts reveal 'lack of fusion' defects for $\geq 400 \mathrm{~mm} / \mathrm{s}$ laser scan speeds, whereas parts processed at 400 and $500 \mathrm{~W}$ showcase 'lack of fusion' defects for laser scan speeds above $800 \mathrm{~mm} / \mathrm{s}$ and $1000 \mathrm{~mm} / \mathrm{s}$, respectively. Note that the part processed using $P$ of $400 \mathrm{~W}$ and $v$ of $800 \mathrm{~mm} / \mathrm{s}$ displays both keyhole (denoted by dashed blue-colored arrows) and 'lack of fusion' 
(denoted by red-colored arrows) porosities, indicating the potential keyhole mode instability. Moreover, the presence of both types of porosity is also observed for the 300 and $500 \mathrm{~W}$ laser power processed parts at the 400 and $1000 \mathrm{~mm} / \mathrm{s}$ laser scan speeds, respectively. This indicates that the parts that contain both types of pores could potentially correspond to the transition region between the conduction and keyhole mode melting. Comparing the melt pool observations made in Figure 3 and the porosity types witnessed in Figure 4, the unstable melt tracks could be linked to the 'lack of fusion' regime. On the other hand, the stable melt tracks could be associated with the keyhole regime (which comprises the keyhole prior to the onset of porosity, i.e., keyhole without porosity and the keyhole-induced porosity sub-regimes).

Comparing the applied L-PBF settings, porosity type, relative part densities, and the melt pool aspect ratios, it could be stated that: (a) A 'lack of fusion' porosity is obtained when the applied L-PBF setting generates a melt pool with an aspect smaller than 1, (b) A keyhole porosity is formed when the L-PBF setting produces a melt pool with an aspect ratio larger than 1, (c) A bulk solid copper part with near full density is fabricated when the applied L-PBF setting produces a melt pool with an aspect ratio close to 1.5. This means that bulk solid copper components with full density could potentially be fabricated by applying L-PBF parameter settings, which produce keyhole mode melting for the chosen set of powder particle size, powder layer thickness, baseplate material, and the baseplate preheating temperature.

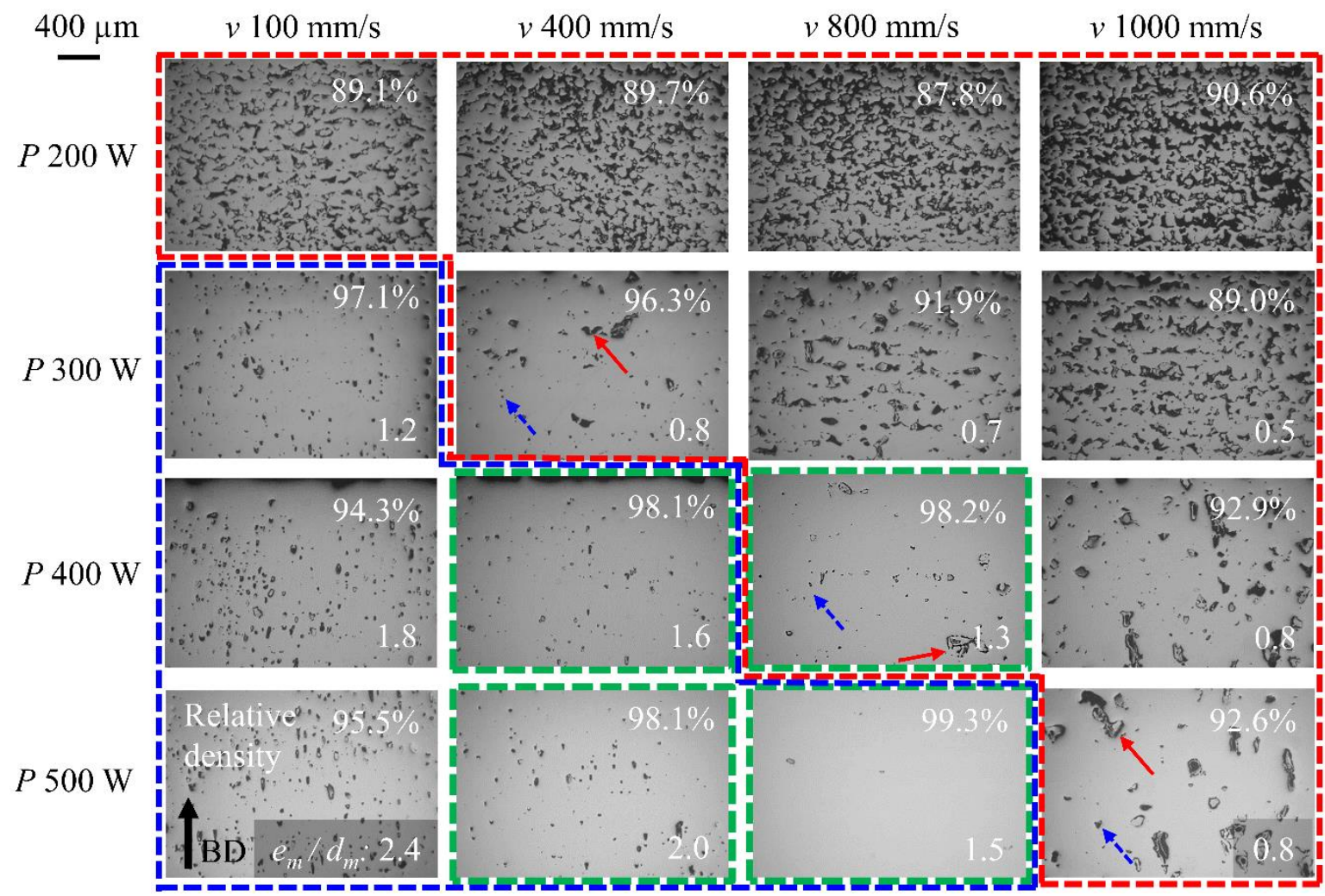

Figure 4: Porosity observation at the as-built cross-sectional surface of the samples produced using laser power $(P)$ levels of 200, 300, 400, and $500 \mathrm{~W}$ and laser scan speed $(v)$ levels of 100, 400, 800, and $1000 \mathrm{~mm} / \mathrm{s}$. All parts were built employing a $0.03 \mathrm{~mm}$ powder bed layer thickness and a 0.09 $\mathrm{mm}$ hatch spacing. Note that the scale bar is indicated at the top left corner of the Figure.

\subsubsection{Melt pool dimension analysis}

Figure 5 displays the evolution of experimentally measured (a \& b) melt pool depth $\left(\mathrm{e}_{m}\right)$ and $(\mathrm{c}$ $\&$ d) width $\left(d_{m}\right)$ as a function of applied laser power $(P)$ levels of 300 to $500 \mathrm{~W}$ and scan speed $(v)$ 
levels of 100 to $1000 \mathrm{~mm} / \mathrm{s}$, respectively. The methodology used for the measurement of melt pool dimensions is illustrated in Supplementary Figure 3. The data points for the melt pool dimensions (width or depth) are connected using smooth lines for all laser power or scan speed levels, and the equations corresponding to linear fits are given in respective images. In general, at the same $v$, a part processed with a higher $P$ displays relatively a higher melt pool depth, except for $1000 \mathrm{~mm} / \mathrm{s}$ processed parts. Moreover, at the same applied $P$, a part processed with a higher $v$ generally yields a lower melt pool depth. The variation in the melt pool depth as a function of the applied $P$ or $v$ clearly indicates that the $P$ has a significant influence on the melt pool depth followed by $v$, inside the chosen array of L-PBF settings. Figures 5(c \& d), however, shows slightly different behavior for the melt pool width compared to the melt pool depth. As seen in Figure 5(c), the melt pool width values of all 100 or $1000 \mathrm{~mm} / \mathrm{s}$ processed parts are rather similar regardless of the employed $P$. Note that although the $300 \mathrm{~W}$ processed parts show slightly lower average melt pool width, the standard deviations of widths of the 300,400 , and $500 \mathrm{~W}$ processed parts overlap with each other at the $v$ of 100 and $1000 \mathrm{~mm} / \mathrm{s}$. Moreover, the $500 \mathrm{~W}$ processed parts show saturation in the melt pool width when processed within a $v$ range of $100-800 \mathrm{~mm} / \mathrm{s}$. However, the saturation in the width of the melt pool is not observed for the 300 and $400 \mathrm{~W}$ processed parts (perhaps the saturation exists below $100 \mathrm{~mm} / \mathrm{s}$ ); rather, a continuous decrease in the melt pool width is observed with increasing $v$. Besides, the parts processed using lower $P$ levels show a slightly higher standard deviation compared to the parts processed using higher $P$ levels. The decreasing trend of the average melt pool depth and width and the corresponding high standard deviations, when using a higher $v$ and/or lower $P$, could potentially be linked to the dynamic keyhole mode melt pool instabilities. On the other hand, the saturation in the melt pool width of $500 \mathrm{~W}$ processed parts could be related to the stability of the keyhole. Finally, the similarity of the melt pool depth and width observed at the $v$ of $1000 \mathrm{~mm} / \mathrm{s}$ could be associated with the formation of conduction-controlled melt pools. 

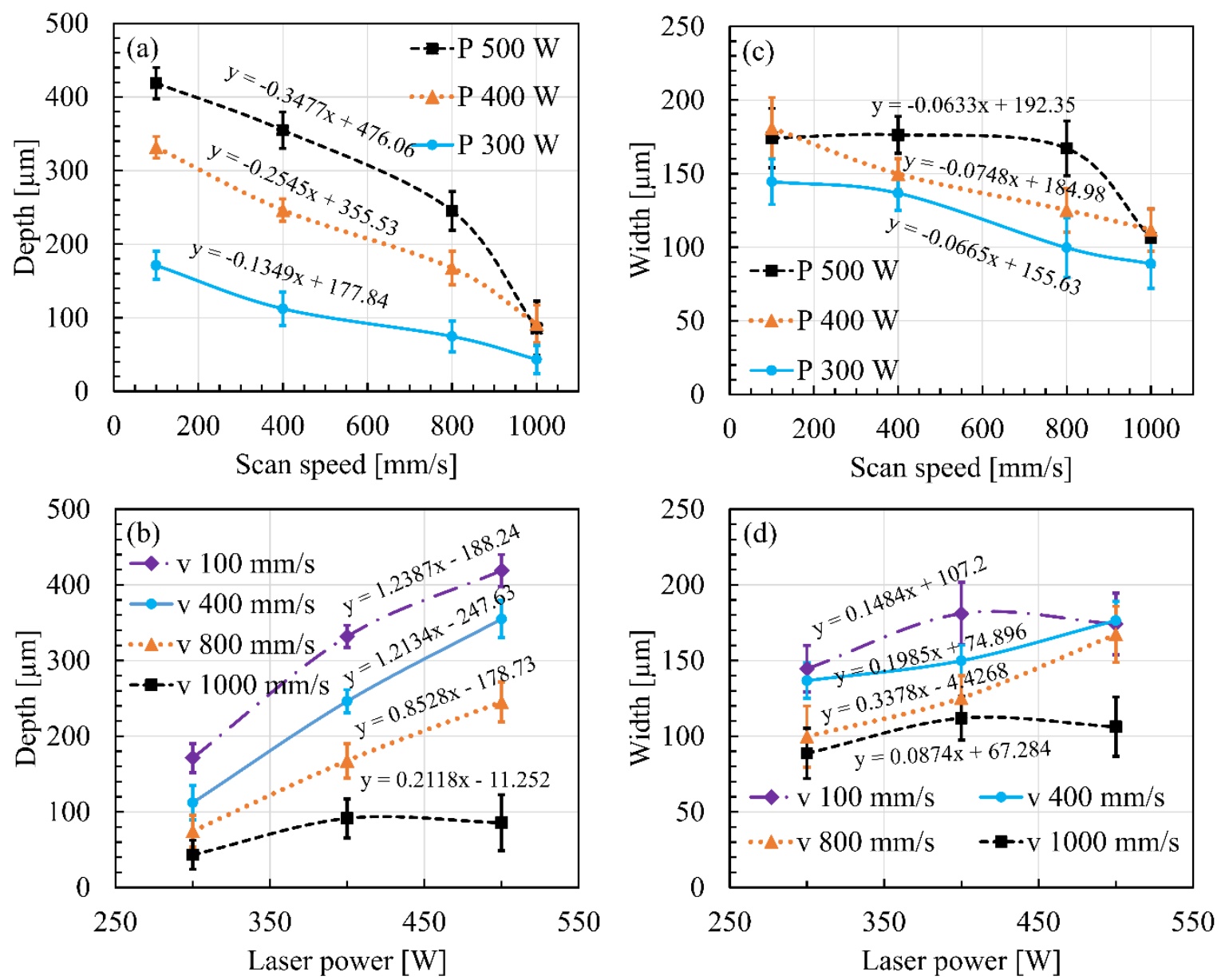

Figure 5: The evolution of experimentally measured melt pool (a \& b) Depth $\left(e_{m}\right)$ and (c \& d) Width $\left(d_{m}\right)$ as a function of laser scan speed $(v)$ and laser power $(P)$, respectively. The average and standard deviation for the melt pool depth and width are reported after the measurement of a minimum of fifteen non-remelted pools present in the final solidified layer of the as-built part.

\subsubsection{Microstructural analysis of a near full density bulk solid copper part}

Figure 6 shows SEM images of the microstructure present on the cross-sectional surface of a $99.3 \%$ $(\rho$ optical $=99.8 \pm 0.1 \%)$ dense copper part at various magnification levels. The melt pool half-width and depth are denoted by aqua-green and orange-colored double-sided arrows, respectively. The cellular dendritic orientation is marked using yellow-colored arrows or a dot.

In the overview image taken at low magnification (100x, Figure 6(a)), porosities and melt pools are not visible. At 250x magnification (Figure 6(b)), obvious porosity is absent; however, the melt pools are clearly visible within the final non-remelted layer, while in the part core, i.e., within re-melted layers, the melt pools lack visibility due to the epitaxial evolution of columnar grains parallel to the building direction (BD) and the existence of a planar solidification front, as validated earlier in [16]. As such, a cellular dendritic sub-grain structure is observed within the microstructure of the final nonremelted layer, and the cellular dendrites present in the final non-remelted layer are oriented perpendicular to the borders of the melt pools or pointing out of the visual plane, as shown in Figures 6(c \& d). This result is consistent with earlier observations [16], where it was reported that they are oriented parallel and opposite to the average temperature gradient. Overall, a single-phase alpha copper microstructure is observed in the part, which is validated by the XRD analysis shown in Supplementary Figure 4. Note that the L-PBF fabricated part contains a very low amount of oxygen ( $54 \mathrm{ppm}$ ). However, 
the $\mathrm{Cu}$-oxide phases, if present, remain undetected in both optical microscopy and the XRD techniques. For XRD technique, they may fall below its detection limit.
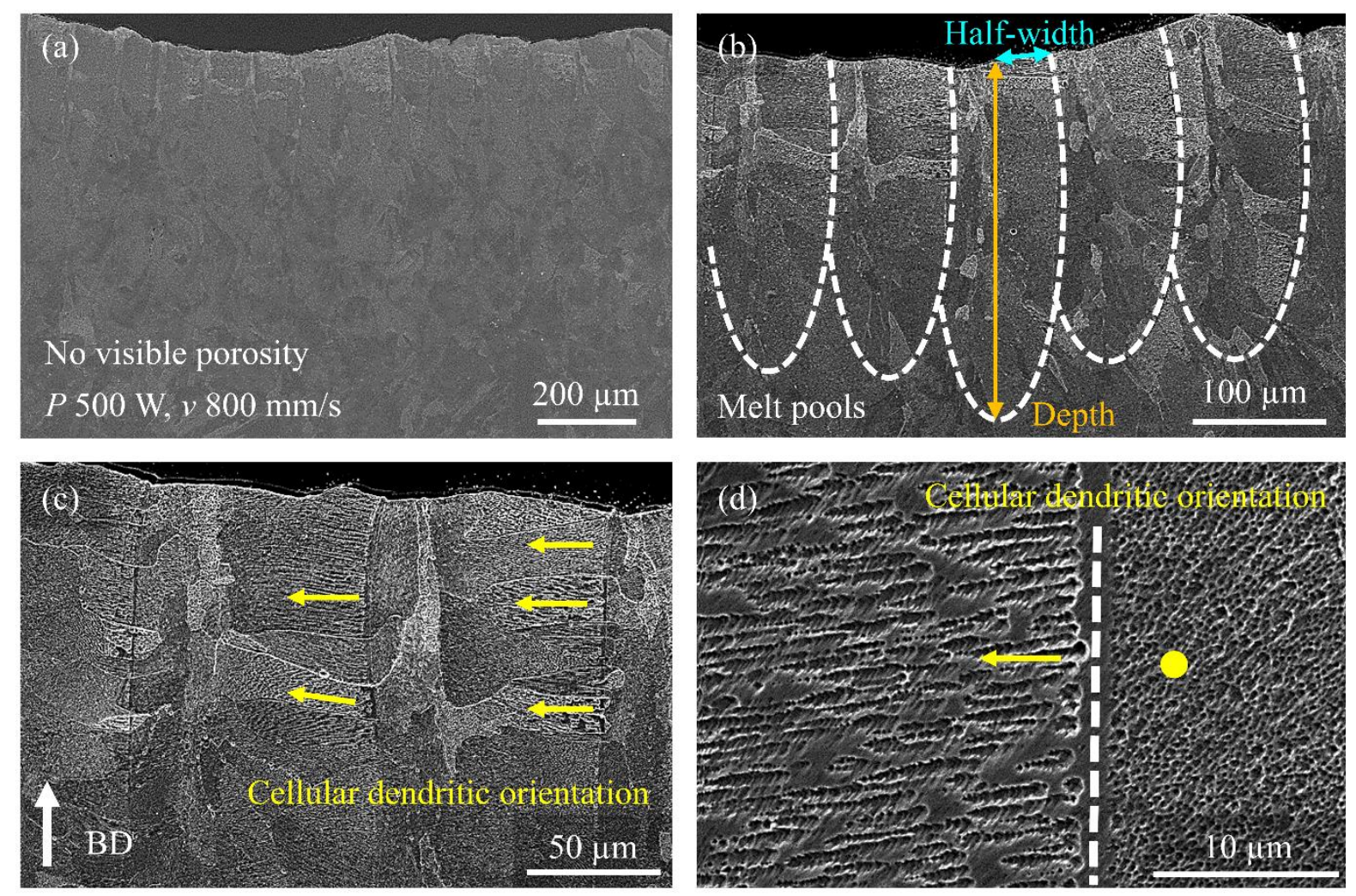

Figure 6: SEM images at different magnifications ((a) 100x, (b) 250x, (c) 500x, (d) 3500x) of the microstructure of a bulk solid copper part with near full density ( $\rho$ Archimedes $=99.3 \pm 0.2 \%, \rho$ optical $=$ $99.8 \pm 0.1 \%$ ) produced by applying the optimized L-PBF settings ( $P$ of $500 \mathrm{~W}$ and $v$ of $800 \mathrm{~mm} / \mathrm{s}$ ) present at the cross-sectional surface.

\subsubsection{The as-built properties of the near full density bulk solid copper part}

Table 5 shows the electrical, thermal, and mechanical properties of the as-built $99.3 \%$ ( $\rho$ optical $=$ $99.8 \pm 0.1 \%$ ) dense copper parts fabricated in this research (denoted as pure Cu L-PBF). Moreover, an overview of the corresponding properties of (near) dense pure copper parts produced by the L-PBF [2527], EBM processes [28], and conventionally processed $99.99 \%$ purity copper (C10100) in wrought condition [29] are provided for reference. As seen, the as-built electrical conductivity and thermal conductivity of copper parts fabricated in the current research are higher compared to the respective conductivities obtained in the prior studies on L-PBF of pure copper [26,27]. The significant improvement in the electrical and thermal conductivities of the L-PBF processed copper parts of the current research could be attributed to the improved densification and chemical purity of the copper part. However, electrical and thermal conductivities measured in the current research are slightly lower compared to the EBM processed copper (C10200) [28] and conventionally processed pure copper (C10100) in the wrought condition [30]. It is worth to note that as per the ASM handbook on copper and copper alloys [30], the $\mathrm{C} 10200$ copper at $20^{\circ} \mathrm{C}$ should exhibit a maximum electrical conductivity of $101 \%$ IACS and a maximum thermal conductivity of $391 \mathrm{~W} /(\mathrm{m} \cdot \mathrm{K})$. However, the electrical conductivity of $\approx 102 \%$ IACS and thermal conductivity of $\approx 412 \mathrm{~W} /(\mathrm{m} \cdot \mathrm{K})$ were measured on the EBM processed pure copper (C10200) parts [28]. This indicates that the conductivity values reported for the EBM processed copper parts are potentially overestimated. Although this might be true, the electrical 
conductivity of the L-PBF processed copper parts reported in this research is about 5 - 6\% IACS lower than the expected electrical conductivity value of the oxygen-free pure copper (i.e., C10100 or C10200). Since the electrical conductivity of copper is very sensitive to impurity elements [31,32], the major part of the 5 - $6 \%$ IACS reduction could be attributed to the $100-200 \mathrm{ppm}$ of impurities that are present in the L-PBF fabricated copper part (refer to Table 1). Moreover, other factors such as porosity of $\approx 0.7 \%$ (as per the Archimedes density measurements) [33], measurement of electrical conductivity perpendicular to the building direction (BD) [34], dislocations, and fine-grain microstructure [35] of the L-PBF processed part could have also contributed to the lowering of the electrical conductivity.

Regarding mechanical properties, the pure copper parts fabricated in this research demonstrate lower mechanical strengths but higher elongation at break compared to the other L-PBF processed copper parts [25-27]. This could be attributed to the minimal presence of impurity elements that form (semi) coherent precipitates or phases (e.g., Cu oxide) in the copper matrix, which improve mechanical strengths of the as-built L-PBF fabricated parts, as validated in [27]. Moreover, the high elongation at break could be linked to the high density ( $\rho_{\text {Archimedes }}=99.3 \pm 0.2 \%, \rho$ Optical $=99.8 \pm 0.1 \%$ ) of the L-PBF copper parts obtained in this research. On the other hand, the L-PBF fabricated parts exhibit a higher yield strength compared to the EBM processed copper parts. The higher yield strength of the L-PBF fabricated parts could be credited to the presence of a fine grain microstructure caused by the very high solidification rates experienced during a typical L-PBF process and the high dislocation density in the as-built condition [25,36]. Lastly, the mechanical properties of the L-PBF fabricated pure copper parts are comparable to the $\mathrm{C} 10100$ copper in wrought condition. Hence, the proposed approach of using an infrared laser with power levels up to $500 \mathrm{~W}$ combined with a fine laser focal spot diameter of $37.5 \mu \mathrm{m}$, for the production of bulk solid copper parts with full density can be used to manufacture highperformance electrical and thermal management components. Although these results demonstrate the successful fabrication of near full density bulk copper parts, the fabrication of real components with complex geometry would require further tuning of the L-PBF parameters that are specific to the shape and size of the geometrical features under consideration.

Table 5: Summary of electrical, thermal, and tensile properties of the $99.3 \%$ ( $\rho$ optical $=99.8 \pm 0.1 \%$ ) dense as-built L-PBF fabricated pure copper parts. The corresponding properties of near dense LPBF [25-27], EBM processed [28], and conventionally processed $99.99 \%$ purity copper (C10100) in wrought condition [30] are provided for reference. Note that $\mathrm{C} 10200$ refers to a $99.95 \%$ purity oxygen-free copper, and C10100 refers to a $99.99 \%$ purity oxygen-free electronic copper.

\begin{tabular}{|c|c|c|c|c|c|c|}
\hline Property & $\begin{array}{l}\text { Pure Cu } \\
\text { L-PBF }\end{array}$ & $\begin{array}{c}\text { Pure Cu } \\
\text { L-PBF } \\
{[25]}\end{array}$ & $\begin{array}{c}\text { Pure Cu } \\
\text { L-PBF } \\
{[26]}\end{array}$ & $\begin{array}{c}\text { Oxidized } \\
\text { Cu } \\
\text { L-PBF } \\
{[27]}\end{array}$ & $\begin{array}{c}\text { Pure Cu } \\
\text { C10200 } \\
\text { EBM [28] }\end{array}$ & $\begin{array}{c}\text { Pure Cu } \\
\text { C10100 } \\
{[30]}\end{array}$ \\
\hline $\begin{array}{l}\text { Electrical conductivity } \\
\text { [IACS \%] }\end{array}$ & $94 \pm 1$ & - & $41 \pm 4$ & 89 & $\approx 102$ & $\leq 102$ \\
\hline $\begin{array}{l}\text { Thermal conductivity } \\
{[\mathrm{W} /(\mathrm{m} \cdot \mathrm{K})]}\end{array}$ & $392 \pm 6$ & - & $173 \pm 15$ & 374 & $\approx 412$ & $\leq 398$ \\
\hline Hardness [HV] & $66 \pm 1$ & $84 \pm 4$ & $84 \pm 5$ & $91 \pm 3$ & - & $51-104$ \\
\hline Tensile strength $[\mathrm{MPa}]$ & $211 \pm 4$ & $248 \pm 9$ & $242 \pm 8$ & $260 \pm 12$ & $177 \pm 3$ & $221-455$ \\
\hline Yield strength [MPa] & $122 \pm 1$ & $187 \pm 5$ & $186 \pm 6$ & $190 \pm 4$ & $78 \pm 1$ & $69-365$ \\
\hline
\end{tabular}




\subsubsection{Fracture analysis}

Figure 7 shows SEM images at different magnifications of the fractured surface of a tensile tested sample. An obvious necking is visible in Figure 7(a), indicating that the tensile bar has been fractured in a ductile mode. Moreover, a high magnification image shown in Figure 7(b) demonstrates a typical dimple fracture morphology corresponding to a ductile fracture mode. The fractured plane does not show evidence of any obvious porosity. Hence, by assimilating the results of density measurements ( $\rho$ Archimedes $=99.3 \pm 0.2 \%, \rho$ Optical $=99.8 \pm 0.1 \%$ ), the top and cross-section surface observations (stable melt pool without porosity), and the tensile test results (high elongation at break value and a ductile fracture morphology), it can be stated that bulk solid copper components with near full density have been successfully fabricated via the infrared fiber laser $(\lambda=1080 \mathrm{~nm})$ based L-PBF process.
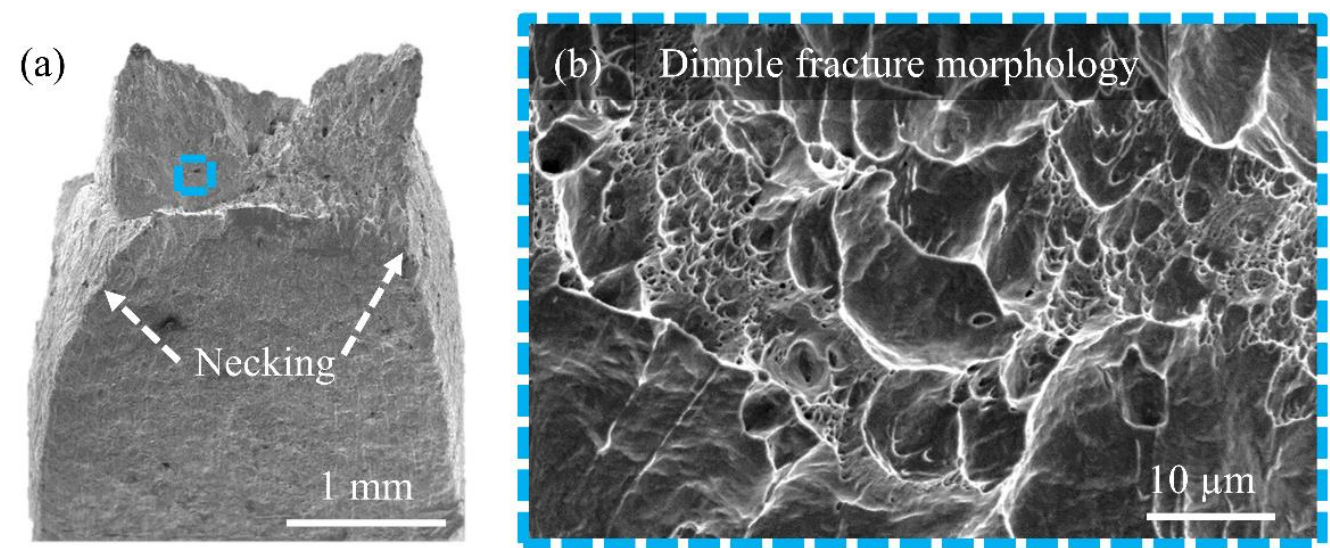

Figure 7: SEM images at different magnifications ((a) 25x, (b) 2000x) of the fractured surface of a tensile tested sample. The sample shows a typical ductile fracture exhibiting necking as well as dimple fracture morphology at the fracture surface.

\subsection{The analytical model predictions}

\subsubsection{The analytical model validation}

The performance of the analytical model represented by Equations $(1-4)$ is evaluated by comparing the theoretically calculated model-based melt pool aspect ratios to the corresponding experimentally measured values (i.e., the depth-to-width ratios reported at the bottom-right side of all images in Figure 4). The model-based melt pool aspect ratios were calculated using the thermophysical properties of pure copper at the melting temperature, as reported in Table 4. Furthermore, the calculated aspect ratios are plotted in Figure 8, along with the experimentally measured ratios. Accordingly, Figure 8 shows a three-dimensional process map, wherein the $\mathrm{x}$-axis and $\mathrm{y}$-axis represent the laser scan speed and laser power, respectively, while the z-axis displays the melt pool aspect ratio $\left(R=\frac{e_{m}}{d_{m}}\right)$. In this Figure, the gray-colored plane denotes the theoretically calculated (predicted) ratios, while the greencolored plane outlined by black-colored square markers represents the experimentally measured ratios.

When comparing the model-based melt pool aspect ratios to the experimentally measured ratios, overall, an average relative error of only $3.9 \%$ is observed with a standard deviation of $19.2 \%$. Although the standard deviation seems higher, it is worth noting that the experimentally measured melt pool depth and width also exhibited high average standard deviations of $18.5 \%$ and $12.5 \%$, respectively (as reported in Figure 5). This illustrates the innate dynamic nature of the L-PBF process via large variances on the melt pool dimensions, even after using the same L-PBF settings for the fabrication of 
the individual part. Evidently, a model that assumes steady-state conditions cannot precisely emulate the observed dynamic melting behavior. However, the standard deviation of the average error (19.2\%) is of comparable magnitude to the standard deviation of the measured melt pool dimensions (18.5 and $12.5 \%$ ), and the observed model errors are close to or within the observed variations of the melt pool dimensions. Therefore, a satisfying performance over a large range of L-PBF settings could be achieved. Note that at the higher melt pool aspect ratios, i.e., $\mathrm{R} \approx 1.5$ or higher, the analytical model slightly underestimates the melt pool aspect ratios compared to the experimentally measured aspect ratios. A possible explanation could be the underestimation of the substrate temperature due to the complex nature of the thermal history occurring during the process. Moreover, other factors such as scan strategy, vector length, part geometry, and scan speed are also known to influence the background temperature. However, no such effect is included in the model formulation. Nevertheless, the mentioned deviation is significantly reduced or even diminished when the melt pool approaches an aspect ratio close to 1 . This indicates that the model is fairly accurate at $\mathrm{R} \approx 1$; consequently, the transition between the conduction to the keyhole regime can be predicted accurately. Hence, it can be stated that, overall, the melt pool aspect ratios predicted by the analytical model are rather in good agreement with the experimentally measured ratios for the chosen range of L-PBF settings, and that the threshold value ( $R$ $\geq 1$ ) for the transition between the conduction to keyhole regime could be identified with acceptable accuracy.

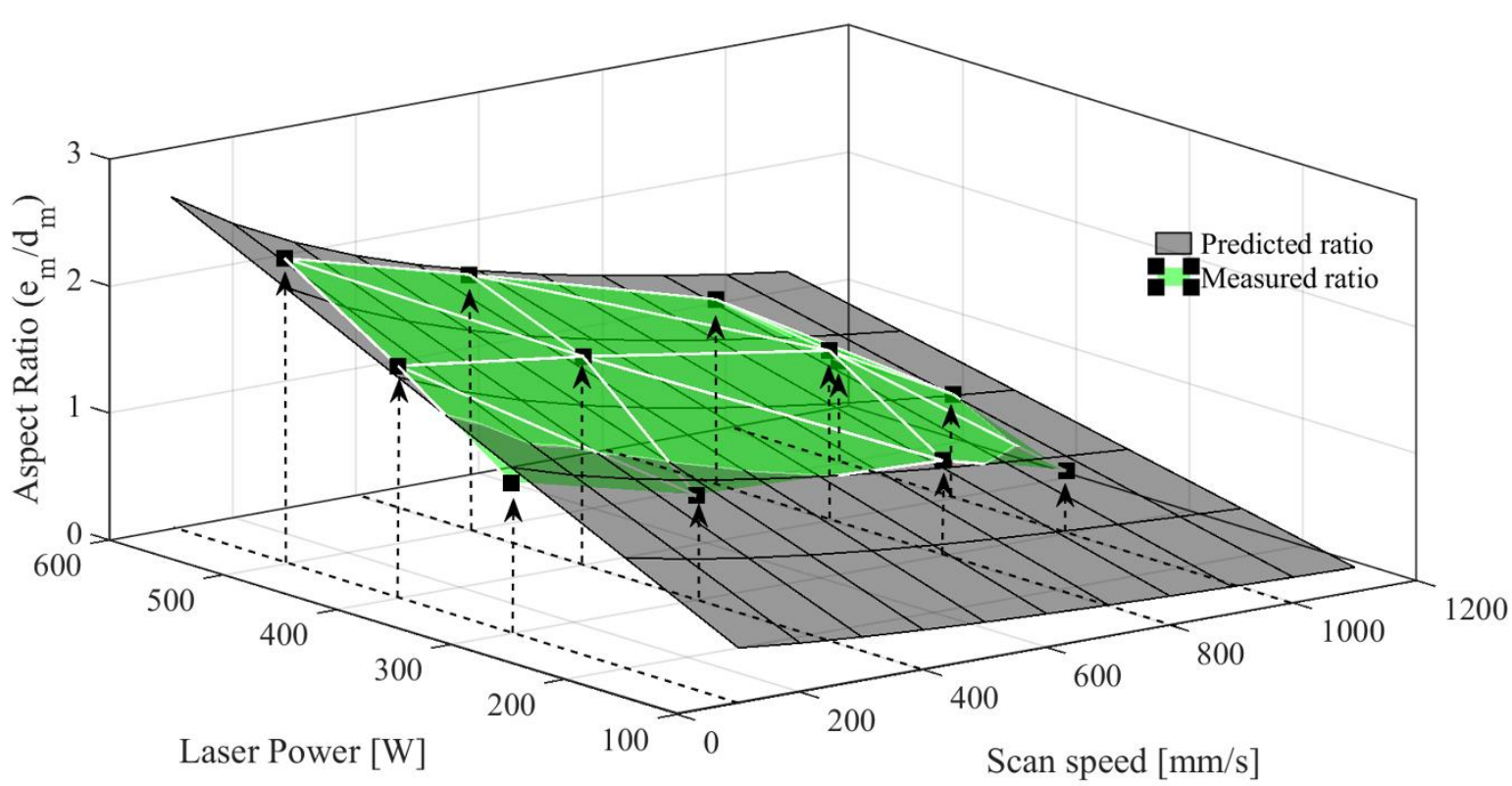

Figure 8: A plot of experimentally measured and theoretically calculated (predicted) model-based melt pool aspect ratios (depth-to-width) is provided in comparison with the applied laser scan speed and laser power.

\subsubsection{Conduction to keyhole mode melting threshold identification}

Fabbro et al. [20] revealed that a sufficient condition for determining the threshold between conduction and keyhole mode melting is the melt pool front reaching an inclination angle exceeding $45^{\circ}$. Reaching this inclination angle marks the beginning of the keyhole phenomenon (i.e., at this stage, the geometry of the melt pool allows the incoming laser light to penetrate within and reflect multiple times on the sidewall of the keyhole before getting absorbed). Furthermore, the authors [20] demonstrated that this condition is similar to that of a melt pool reaching an aspect ratio of 1 (i.e., $e_{m}=$ $d_{m}$ ). Consequently, the melt pool aspect ratio of 1 could be considered as the threshold value for the initiation of the keyhole mode melting, and the keyhole regime could be identified as the regime where 
the melt pools exhibit aspect ratios of $\mathrm{R} \geq 1$. Applying this criterion, a process map is plotted using the model-based melt pool aspect ratios in Figure 9 for the chosen range of laser powers and scan speeds. In Figure 9, the light-gray and dark-gray-colored regions denote conduction and keyhole regimes, respectively, and the white-colored line represents the transition between conduction and keyhole regimes. The LOM images of the cross-sectional surface are also displayed for the corresponding LPBF processing conditions. The solid red-colored and dashed blue-colored arrows signify the presence of 'lack of fusion' and keyhole porosity, respectively. The cross-sectional surface with both red and blue-colored arrows indicates that the part contains a mix of both types of porosities. The highest density L-PBF fabricated copper parts corresponding to each laser power level are indicated using yellowcolored stars. Note that the cross-sectional surface is only displayed for the highest density part processed at $500 \mathrm{~W}$ (i.e., $P$ of $500 \mathrm{~W}$ and $v$ of $800 \mathrm{~mm} / \mathrm{s}$ ), while it is not shown for the highest density parts processed at $300 \mathrm{~W}$ (i.e., $P$ of $300 \mathrm{~W}$ and $v$ of $200 \mathrm{~mm} / \mathrm{s}$ ) and $400 \mathrm{~W}$ (i.e., $P$ of $400 \mathrm{~W}, v$ of 600 $\mathrm{mm} / \mathrm{s})$.

As seen, all parts processed within the conduction regime reveal 'lack of fusion' porosity, whereas the parts that belong to the keyhole regime display near full density or keyhole-induced porosity. As such, all highest density copper parts corresponding to each power level are located within the keyhole regime, but close to the conduction-keyhole transition line. This means that the laser settings which generate melt pool aspect ratios far off from unity (i.e., $\mathrm{R} \gg 1$ or $\mathrm{R}<<1$ ) normally induce porosities, such as keyhole-induced or 'lack of fusion' porosities, which is in agreement with the observations reported by King et al. [37]. Furthermore, the parts that exhibit both types of porosity are generally located nearby the conduction-keyhole transition line demonstrating the instability of the keyhole. Note that the highest density parts processed at 300 and $400 \mathrm{~W}$ do not demonstrate near full density (> 99\%), and this could be associated with the keyhole mode instability, as shown in Figure 5.

Figure 9 shows that the keyhole mode melting could be initiated by employing a minimum of $\approx 250 \mathrm{~W}$ laser power (at the scan speed of $100 \mathrm{~mm} / \mathrm{s}$ ), and that the $200 \mathrm{~W}$ laser power is not enough for the generation of the keyhole mode melting for the chosen combination of powder particle size, L-PBF settings, infrared fiber laser focal spot size, and pure copper baseplate. The bulk solid copper part with near full density $(\rho$ Archimedes $=99.3 \pm 0.2 \%, \rho$ optical $=99.8 \pm 0.1 \%$ ), which was fabricated by employing $P$ of $500 \mathrm{~W}$ and $v$ of $800 \mathrm{~mm} / \mathrm{s}$, is located in the keyhole regime, while the $\approx 93 \%$ dense part produced using the $500 \mathrm{~W}$ laser power and $1000 \mathrm{~mm} / \mathrm{s}$ scan speed is located at the conduction-keyhole transition line (or in the conduction regime, since the cross-sectional surface mainly contains 'lack of fusion' porosity). Hence, this drastic decrease in the part density with the increase of laser scan speed from 800 to $1000 \mathrm{~mm} / \mathrm{s}$ could be associated with the keyhole to the conduction mode melting transition. 


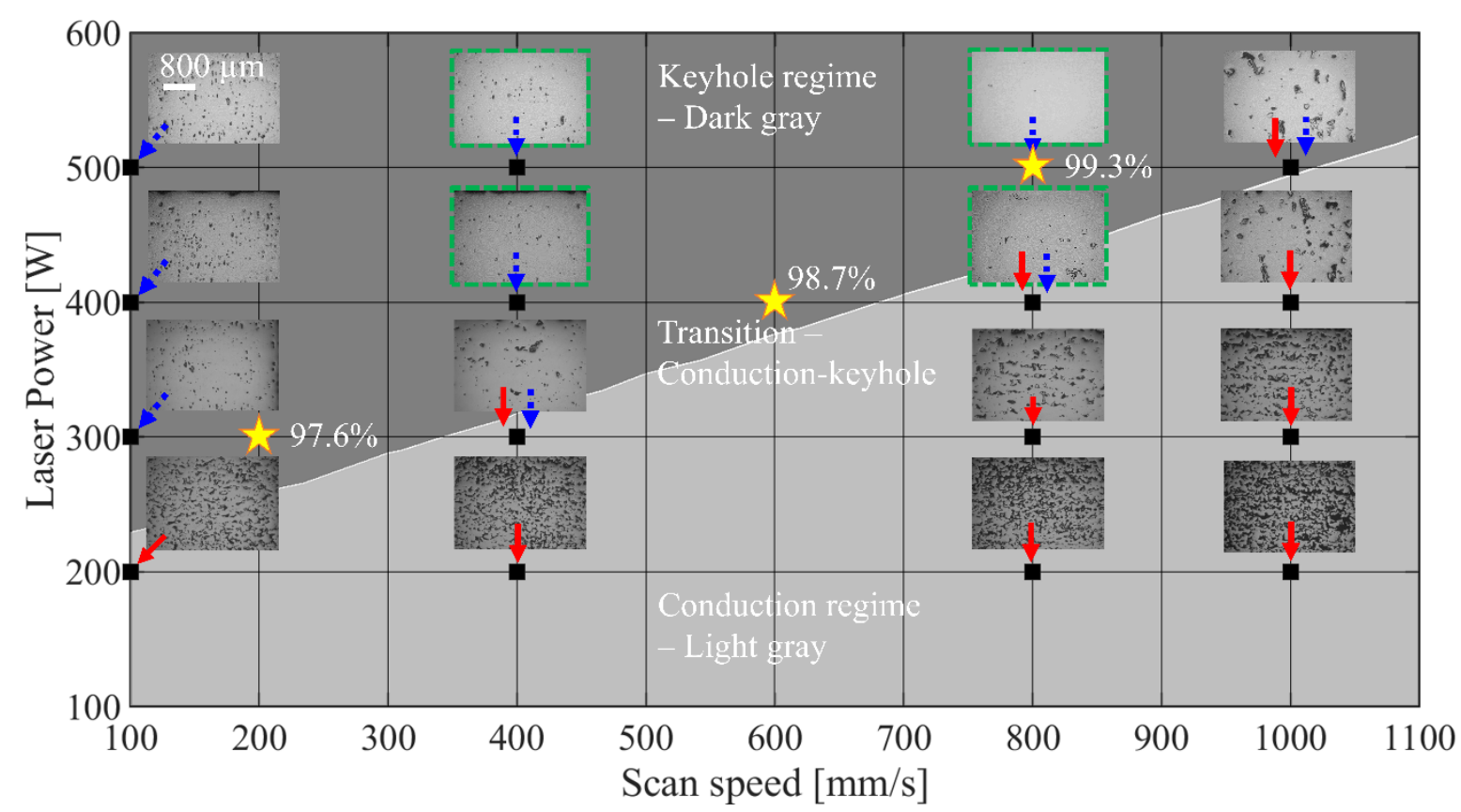

Figure 9: A model-based L-PBF process map of pure copper showing a threshold line between the conduction and keyhole mode melting regimes is plotted in function of the applied laser power and scan speed.

\section{Discussion}

\subsection{Understanding the L-PBF processing behavior of pure copper powder}

Figure 2 showed that a peak relative part (Archimedes) density of $\approx 90 \%$ was obtained when a 200 W laser power was used. In Figure 3, all $200 \mathrm{~W}$ processed parts revealed unstable melt tracks with abundant porosity and unmolten powder particles at the top surface, while at the cross-sectional surface, shown in Figure 4, they exhibited 'lack of fusion' defects with merely no attachment between the successively deposited powder layers. Moreover, the model-based process map shown in Figure 9 disclosed that all the $200 \mathrm{~W}$ processed parts fall within the conduction regime. This means that $200 \mathrm{~W}$ laser power is not enough for melting of the copper powder particles, and the L-PBF settings that belong to the conduction regime do not fabricate bulk solid copper parts with full density. This L-PBF processing behavior could be explained by Equation $(5)$ [38,39], which is typically used in laser-based welding processes (or processes wherein the heat-source exhibits a Gaussian intensity distribution profile) for theoretically calculating the lowest laser power that is essential for the initiation of melting at the surface of the substrate material. Solving Equation (5) for copper metal, using $k=330 \mathrm{~W} /(\mathrm{m} \cdot \mathrm{K})$ [22], $d=26.51 \times 10^{-06} \mathrm{~m}$ (1/e value), $T_{m}=1357 \mathrm{~K}$, and $A=0.11$ [40], yields a laser power $\left(W_{m}\right)$ of 191 $\mathrm{W}$. This indicates that the applied laser power of $200 \mathrm{~W}$ is indeed close to the theoretically calculated minimum laser power $(191 \mathrm{~W})$ that is required for the initiation of melting at the surface of a copper substrate. Hence, the applied laser power of $200 \mathrm{~W}$ could be enough to induce partial melting of copper powder but may not be sufficient for the full melting of the copper powder particles. Therefore, all 200 $\mathrm{W}$ processed parts demonstrate low part density values due to the incomplete melting of the copper powder, rendering 'lack of fusion' defects with poor attachment between subsequent powder layers.

$$
W_{m}=\frac{\sqrt{\pi} \times k \times d \times T_{m}}{A}
$$

Where 
$W_{m}$ : The lowest laser power that is essential for the initiation of melting at the material's surface

$[\mathrm{W}]$

\author{
$k$ : Thermal conductivity $[\mathrm{W} /(\mathrm{m} \cdot \mathrm{K})]$ \\ $d$ : Laser focal spot diameter, $1 / \mathrm{e}$ value $[\mathrm{m}]$ \\ $T_{m}$ : Melting temperature $[\mathrm{K}]$ \\ A: Absorptivity
}

On the contrary, since the 300,400 , and $500 \mathrm{~W}$ laser power levels are sufficiently higher than the lowest laser power level that is essential for the initiation of surface melting, the complete melting of copper powder is feasible. Consequently, the $300-500 \mathrm{~W}$ processed parts reveal significant improvement in the part density, as validated in Figures 2 - 4. Note that Equation (5) does not consider the influence of laser scan speed; rather, it assumes that the laser is stationary. However, it is recognized that during the L-PBF process, the laser scan speed (or the laser exposure time) has a substantial influence on the applied volumetric energy density. Hence, an upsurge in the lowest laser power that is essential for the complete melting of copper powder is expected as the laser scan speed is increased (or decrease in the laser exposure time). Consequently, some parts manufactured at higher scan speeds show 'lack of fusion' porosities, even when a laser power output within the $300-500 \mathrm{~W}$ range was used. Figure 9 revealed that the porous parts which contain 'lack of fusion' defects belong to the conduction regime, while the dense parts and the parts with keyhole porosity belong to the keyhole regime (comprised of keyhole without porosity and keyhole-induced porosity sub-regimes). It can be noticed that a part that is processed in the keyhole regime exhibits a relatively higher density compared to a part processed in the conduction regime. The drastic improvement in the part densification behavior when processing in the keyhole regime compared to the conduction regime could be elucidated using a schematic presented in Figure 10.

Figure 10(a), adapted from Fabbro [41], shows an interrelationship between the melt pool aspect ratio and the effective laser absorption based on the in situ laser absorption (optical absorptivity) measurements performed by Trapp et al. [42] on a 316 SS alloy substrate. Moreover, the author [41] incorporated the theoretically calculated laser absorption values using Gouffe's model in Figure 10 (a \& b) for 316 SS, steel, and copper substrates. As seen in Figure 10(a), when the melt pool aspect ratio $(\mathrm{R})$ is $<1$, i.e., conduction regime denoted by $\mathrm{Z} 1$, the effective laser absorption is low, and it does not increase significantly with an increase of laser power. However, when $R \geq 1$, i.e., keyhole and keyholeinduced porosity sub-regimes indicated by Z2 and Z3, respectively, a sudden and continuous increase in the effective laser absorption is observed until it saturates at $R \geq 10$. The authors $[41,42]$ attribute this non-linear rise in the effective laser absorption to the keyhole feature of the melt pool, which allows the laser light to penetrate deep into the melt pool and reflect multiple times on the melt pool sidewalls before getting absorbed. Hence, the keyhole feature can render a non-linear increase in laser absorption, as shown in Figures 10 (d \& e). On the other hand, the low and steady behavior of the effective laser absorption in zone 1 (i.e., rather constant laser absorption value) is attributed to the geometry of the conduction-controlled melt pool that does not have the keyhole feature, and thus it neither allows the penetration of laser light deep into the melt pool nor permits the laser light to reflect internally within the melt pool, as indicated in Figure 10(c). Hence, it can be understood that the effective laser absorption in the conduction regime is mainly governed by the material optical absorptivity, while in the keyhole regime, it is governed primarily by the keyhole feature followed by the material optical absorptivity. Figure 10(a) shows that Gouffe's model predicts a similar laser absorption trend as the experimental measurements of the 316 SS alloy. Furthermore, Figure 10(b) suggests that similar laser absorption behavior could also be expected for steel and copper substrates, which indicates that the results are transferable to highly reflective metals, such as copper. It is worth noting that Gouffe's model 
overestimates the laser absorption values and predicts the conduction-keyhole transition at a melt pool aspect ratio lower than 1 . The author [41] attributes this model-limitation to the difference between the geometry of the real-keyhole and the cone-shaped keyhole geometry that is used in Gouffe's model.

It is known that pure copper exhibits much lower optical absorptivity $(\leq 0.15)$ for the infrared radiations in the solid and liquid state compared to other low thermal conductivity laser-processable alloys $[43,44]$. Consequently, L-PBF processing of pure copper in the conduction regime using infrared fiber laser $(\lambda=1080 \mathrm{~nm})$ is difficult and often results in the fabrication of porous parts with 'lack of fusion' defects due to the inadequate amount of effective laser absorption and the simultaneous fast dissipation of the absorbed heat, as shown in Figure 10(f). However, if pure copper is processed in the keyhole regime, a sufficiently high effective laser absorption that is essential for the complete melting of the copper powder could be achieved via the keyhole geometry-driven laser absorption component, and parts with full density could be fabricated, as shown in Figure 10(g). Although the keyhole feature is attractive for the processing of pure copper, the combined effect of high thermal conductivity $(\approx 400$ $\mathrm{W} /(\mathrm{m} \cdot \mathrm{K}))$ and the inhomogeneous absorption of the laser energy along the keyhole wall (in laser melting of copper, the bottom half of the keyhole absorbs four times more laser energy compared to the upper half of the keyhole, as validated by Zhang et al. in [45]) limits the keyhole stability [46]. As such, the stability of the keyhole during laser-based processes is maintained by realizing an equilibrium between keyhole-opening (ablation or recoil pressure) and keyhole-closing (surface tension, convection pressure, and hydrostatic pressure) forces [37,46-48]. Since the high thermal conductivity of copper enables the rapid dissipation of the absorbed heat, the keyhole-closing forces during solidification can rise quickly in the upper part of the copper keyhole mode melt pool compared to the other low thermal conductivity metals and alloys [46]. Moreover, along with the high thermal conductivity, the rise of the keyhole-closing forces, especially in the upper half of the keyhole wall are assisted by the inhomogeneous distribution of the laser energy along the high reflectivity copper keyhole wall compared to the low reflectivity metal or alloy keyhole wall [45]. Hence, during solidification, a relatively shorter time is available for filling and closing of the keyhole with liquid metal in the case of highly conductive metals, such as pure copper, compared to the low conductivity metals and alloys (i.e., a molten melt pool made of a highly conductive metal, such as copper, will solidify faster compared to the molten melt pool made of a low conductivity metal). This increases the possibility of trapping vapor bubbles during the solidification of the melt and often results in keyhole-induced porosity formation. Furthermore, this could limit the removal of inclusions through the occurrence of remelting and buoyance forces when processing subsequent layers [49]. Consequently, a relatively smaller L-PBF processing window is obtained for the manufacture of fully dense parts made of highly conductive metals, such as pure copper, when a laser with $1080 \mathrm{~nm}$ wavelength is used. However, since pure copper exhibits a high optical absorption for visible radiations (i.e., at the blue $(\lambda=450 \mathrm{~nm})$ or green $(\lambda=532$ $\mathrm{nm}$ ) laser wavelength), the required effective laser absorption for full melting of copper powder particles might be reached in the conduction mode. Therefore, the use of green or blue laser may broaden the LPBF processing window, and copper parts exhibiting full density could be fabricated in both conduction and keyhole modes, similar to the conventional infrared fiber laser $(\lambda=1080 \mathrm{~nm})$ based L-PBF processing windows of Ti-6Al-4V and SS 316L alloys. Besides, a broader L-PBF processing window against infrared lasers for highly conductive copper and copper alloys can be achieved by utilizing surface-modified copper powders which exhibit high optical absorption, as validated by Jadhav et al. [27,50-52] and Lindström et al. [53]. However, the latter approach is valid when, at least, a small amount of alloying is permitted. Finally, it can be stated that, when using the infrared fiber laser $(\lambda=$ $1080 \mathrm{~nm}$ ) based L-PBF machines, the fabrication of bulk solid copper components starting from (unmodified) pure copper powder can only be achieved in the keyhole mode but prior to the onset of the keyhole-induced porosity sub-regime. 
(a) $316 \mathrm{SS}, v=0.5 \mathrm{~m} / \mathrm{s}$

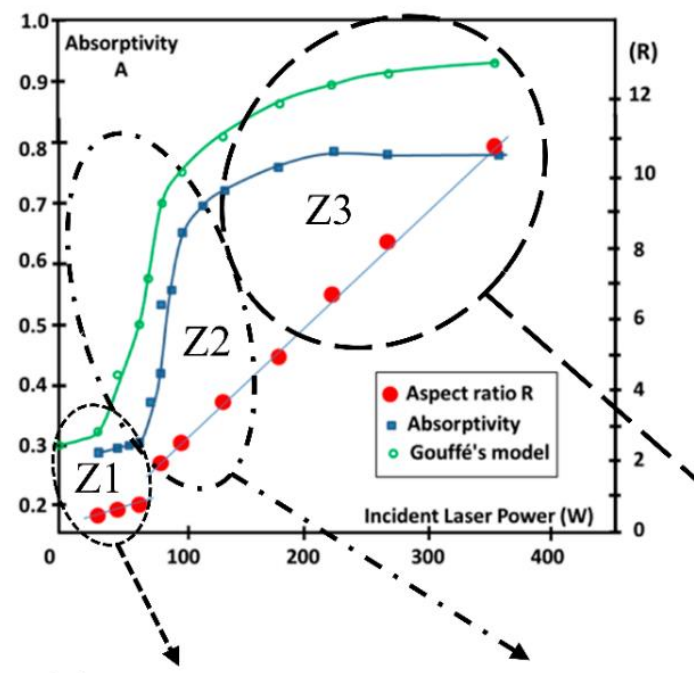

(c) Conduction

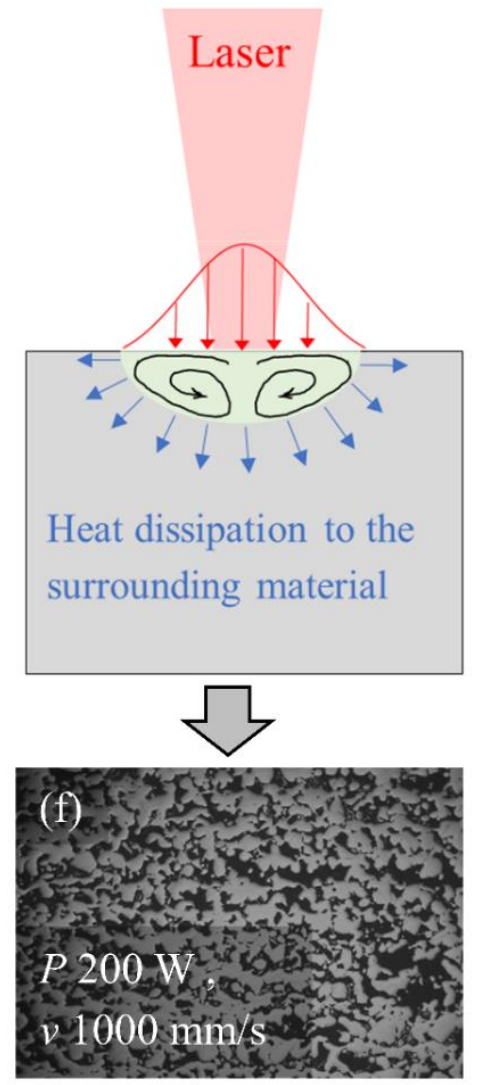

(b) Predicted by Gouffe's model

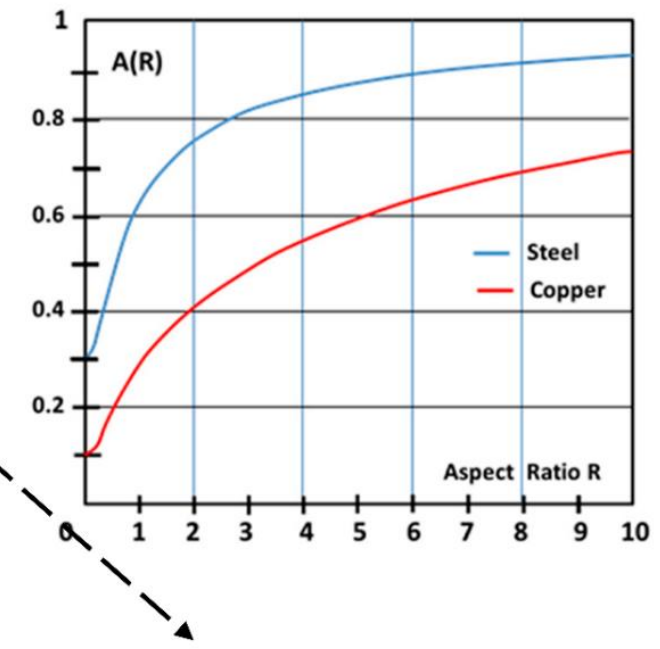

(d) Keyhole

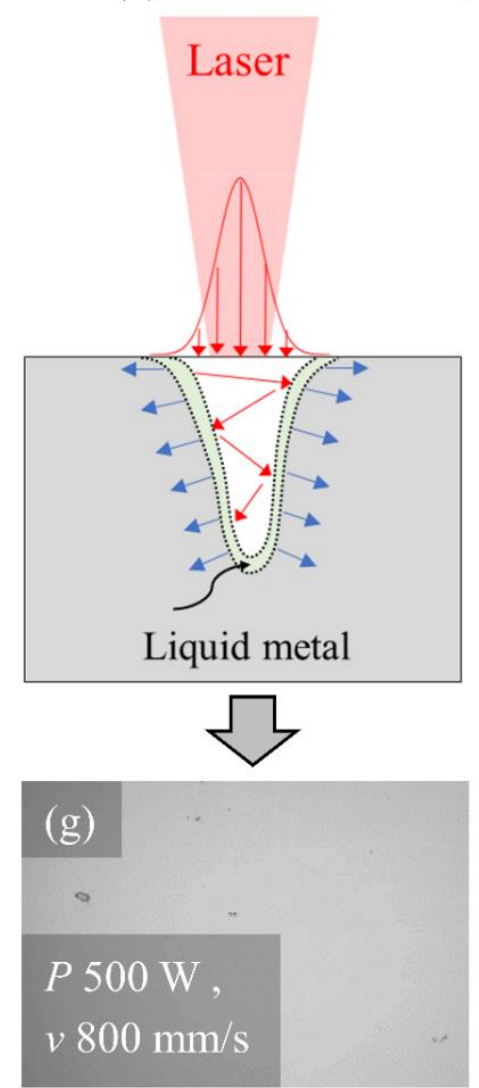

(e) Keyhole-induced porosity
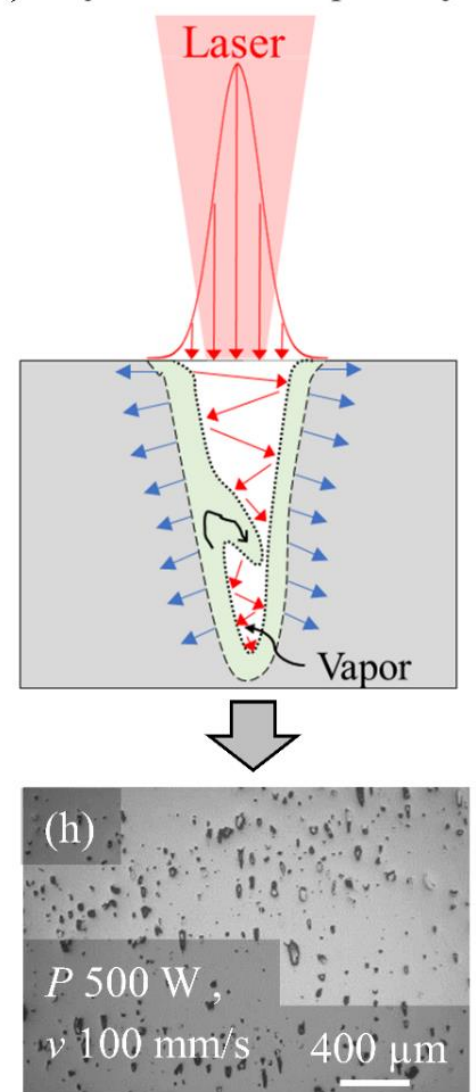

Figure 10: (a) The evolution of effective laser absorption $(A)$ and the melt pool aspect ratio $(R)$ in the function of laser power at a $0.5 \mathrm{~m} / \mathrm{s}$ scan speed and for a $316 \mathrm{SS}$ substrate. The laser absorption measurements were performed by Trapp et al. [42], and Figure (a) was adapted by Fabbro [41] with the incorporation of melt pool aspect ratios and prediction of the laser absorption curve via Gouffe's model. (b) Prediction of the effective laser absorption, A(R), for steel (blue) and copper (red) substrates as a function of the melt pool aspect ratio via Gouffe's model. Figure (b) is reprinted from [41]. Schematic representation of (c) a conduction-controlled, (d) keyhole without porosity, and (e) keyhole-induced porosity melt pools. The schematics presented in Figures $(\mathrm{c}-\mathrm{e})$ are adapted from [54]. Cross-sectional surfaces of pure copper parts processed in (f) conduction, (g) keyhole without porosity, and (h) keyhole-induced porosity, regimes. 


\subsection{The influence of laser power, scan speed, and volumetric energy density on the relative density of parts}

Figure 2 showed that copper parts processed using a similar volumetric energy density could have significantly different part densities, depending on the applied laser scan speed and laser power. This indicated that for highly reflective metals, such as copper, the volumetric energy density alone could not explain the density trend of parts, and the density of the parts can be increased by the application of a lower laser scan speed or a higher laser power. The observed L-PBF processing behavior could be explained using the non-linear effective laser absorption behavior of copper in the keyhole regime compared to the conduction regime, as shown in Figures 9 and 10. As such, the keyhole mode melt pool exhibits much higher effective laser absorption compared to the conduction mode melt pool [46]. Since the production of bulk solid copper parts with full density requires a high effective laser absorption, the L-PBF parameters which have a greater influence on the keyhole mode formation will logically have a greater influence on the part densification, especially in the case of highly conductive and optically reflective metals [50,55]. Consequently, the laser power has the highest influence on the part densification behavior, followed by the laser scan speed inside the designated array of L-PBF settings (However, within a broader L-PBF parameter set, the melt pool depth is supposed to increase linearly with increasing applied laser power, while it is supposed to decrease at $\approx(1 /(1+v))$ rate with increasing laser scan speed (v), refer to Equations $(1 \& 2))$. Moreover, Figure 2 showed that the application of a higher laser power shifts the peak of the part density trend to a lower volumetric energy density value. This behavior can be explained by the rate and the efficiency with which the keyhole mode can be initiated and maintained, respectively, under the applied L-PBF parameter set. Since the application of higher laser power can create a keyhole at a faster rate and generate a sufficient amount of ablation pressure to keep the keyhole open, an increased amount of laser irradiation could be absorbed within the keyhole. Consequently, a sufficient amount of effective laser absorption required to produce a bulk solid copper part with full density could be reached at a lower volumetric energy density value when using a relatively higher laser power.

\section{Conclusions}

In this article, the laser-based powder bed fusion (L-PBF) processing behavior of pure copper powder was evaluated using an infrared fiber laser $(\lambda=1080 \mathrm{~nm})$ exhibiting a small focal spot diameter of $37.5 \mu \mathrm{m}$ and laser power levels up to $500 \mathrm{~W}$. It was shown that a laser power of $500 \mathrm{~W}$ is sufficient for the fabrication of bulk solid copper parts with near full density ( $\rho$ Archimedes $=99.3 \pm 0.2 \%, \rho$ Optical $=$ $99.8 \pm 0.1 \%$ ) for the chosen combination of powder particle size, L-PBF settings, and pure copper baseplate. Furthermore, the part density increases with increasing applied laser power or decreasing laser scan speed. As such, a sudden rise in the relative part density was observed when the applied laser power was changed from 200 to 300, 400, or $500 \mathrm{~W}$. Moreover, parts with a relative (Archimedes) density exceeding $99 \%$ were fabricated within a very small processing window $\left(230-310 \mathrm{~J} / \mathrm{mm}^{3}\right)$, and that the peak of the part density curve was shifted to a lower volumetric energy density value when higher laser power was used. Comparing the Archimedes density results, the melt pool stability as observed from the top surface, the porosity types revealed at cross-sectional surfaces, and the melt pool dimensions, it was established that stable melt tracks observed at the top surface with or without keyhole porosity at the cross-section potentially belong to the keyhole regime, whereas the unstable melt tracks observed at the top surface with 'lack of fusion' defects at the cross-sectional surface could be associated to the conduction regime. To visualize the processing map, an analytical model introduced by Fabbro et al. [20,21] was used. The analytical model considers thermophysical properties of copper to predict a melt pool aspect ratio, i.e., depth-to-width ratio. The melt pool aspect ratio of $\geq 1$ was used to demonstrate the transition from conduction to keyhole mode melting. By comparing the model-based results with the experiments, it was confirmed that the near fully dense part and the parts with keyhole 
porosity indeed belong to the keyhole regime, whereas the parts that contain 'lack of fusion' porosity are located in the conduction regime. Hence, it could be said that, when using the infrared fiber laser $(\lambda$ $=1080 \mathrm{~nm}$ ) based L-PBF machines, bulk solid copper parts with full density made of highly reflective metals, such as copper, could only be fabricated in the keyhole regime prior to the onset of keyholeinduced porosity. The substantial improvement observed in the part density in the keyhole regime was attributed to the keyhole feature, which allows a non-linear increase in the effective laser absorption caused by multiple internal reflections of laser radiations inside the keyhole and subsequent absorption. In contrast, the lower part density observed in the conduction regime is attributed to the absence of the keyhole feature in the conduction-controlled melt pool, which reflects most of the incident laser radiations. Thus, in the conduction regime, an adequate level of effective laser absorption that is essential for melting of the copper powder particles could not be reached, and parts exhibiting 'lack of fusion' defects and low relative density were formed. As such, $200 \mathrm{~W}$ laser power was not enough for melting of the copper powder particles, and therefore low-density parts with unmolten powder particles and poor attachment between subsequent layers were realized. In contrast, a laser power level of 300 $\mathrm{W}$ and higher was sufficient to generate a keyhole mode melt pool, and therefore a substantial improvement in the part density was realized. The presence of a narrow processing window is attributed to the combined effect of the high thermal conductivity $(\approx 400 \mathrm{~W} /(\mathrm{m} \cdot \mathrm{K}))$ of copper and the inhomogeneous absorption of the laser energy along the keyhole wall, which hampers the equilibrium between keyhole-opening and keyhole-closing forces. Finally, the shift of the part density peak to lower volumetric energy density values upon the application of higher laser power is attributed to the rate and the efficiency by which the keyhole mode is initiated and maintained, respectively. Since the use of a higher laser power allows immediate initiation and stabilization of the melt pool, a relatively lower amount of energy is needed to fabricate a bulk solid copper part with near full density, and therefore the peak of the part density curve is shifted to a lower volumetric energy density level. The bulk solid copper part with near full density fabricated via L-PBF showed an excellent amalgamation of electrical (94 $\pm 1 \%$ IACS), thermal $\left(392 \pm 6 \mathrm{~W} /(\mathrm{m} \cdot \mathrm{K})\right.$ ), and mechanical (hardness of $66 \pm 1 \mathrm{HV}_{0.3}$, yield strength of $122 \pm 1 \mathrm{MPa}$, tensile strength of $211 \pm 4 \mathrm{MPa}$, and elongation at break of $43 \pm 3 \%$ ) properties.

Overall, this investigation demonstrates that bulk solid copper components with near full density can successfully be produced using an infrared fiber laser $(\lambda=1080 \mathrm{~nm})$ based L-PBF machine, provided that the employed L-PBF settings are adequate to generate the keyhole mode melting. Moreover, the required laser power for the production bulk solid copper components with full density could further be reduced below $500 \mathrm{~W}$ by altering the L-PBF settings, powder particle size, baseplate material, and the baseplate pre-heating temperature in such a way that they assist in the generation and stabilization of keyhole mode melting. Although the formation of the keyhole mode melting is necessary for the production of bulk solid copper components with full density in infrared fiber laser $(\lambda$ $=1080 \mathrm{~nm}$ ) based L-PBF machines, it may not be necessary when using the surface-modified copper powders with high optical absorption for the infrared lasers or the L-PBF machines equipped with a blue or green lasers for which copper has a high optical absorptivity. As such, the use of both surfacemodified copper powders with high optical absorption for infrared lasers and blue or green lasers may broaden the L-PBF processing window of copper, and bulk solid copper components with full density could be produced in both the conduction and keyhole modes, similar to the conventional infrared fiber laser-based L-PBF processing windows of Ti-6Al-4V and SS 316 $\mathrm{L}$ alloys. 


\section{Acknowledgments}

For this work with the project title '3D-Cu: 3D printing of highly conductive copper powders', we received joint funding with the contract number - HBC.2017.0479. The authors are thankful to the following funding company and agency.

(1) Aurubis Belgium SA/NV

(2) Agentschap Innoveren en Ondernemen (VLAIO))

\section{Competing Interests Statement}

No known competing interests.

\section{Data Availability}

The authors can provide raw or processed data upon request. 


\section{References}

[1] R. Wrobel, B. Mecrow, A Comprehensive Review of Additive Manufacturing in Construction of Electrical Machines, IEEE Trans. Energy Convers. 35 (2020) 1054-1064. doi:10.1109/TEC.2020.2964942.

[2] D. Jafari, W.W. Wits, The utilization of selective laser melting technology on heat transfer devices for thermal energy conversion applications: A review, Renew. Sustain. Energy Rev. 91 (2018) 420-442. doi:10.1016/j.rser.2018.03.109.

[3] T.J. Horn, D. Gamzina, Additive Manufacturing of Copper and Copper Alloys, in: Addit. Manuf. Process., ASM International, 2020: pp. 388-418. doi:10.31399/asm.hb.v24.a0006579.

[4] T.Q. Tran, A. Chinnappan, J.K.Y. Lee, N.H. Loc, L.T. Tran, G. Wang, V.V. Kumar, W.A.D.M. Jayathilaka, D. Ji, M. Doddamani, S. Ramakrishna, 3D Printing of Highly Pure Copper, Metals (Basel). 9 (2019) 756. doi:10.3390/met9070756.

[5] R. Neugebauer, B. Müller, M. Gebauer, T. Töppel, Additive manufacturing boosts efficiency of heat transfer components, Assem. Autom. 31 (2011) 344-347. doi:10.1108/01445151111172925.

[6] H. Irrinki, S.D. Nath, A.A. Akilan, S. V. Atre, Laser Powder Bed Fusion, in: Addit. Manuf. Process., ASM International, 2020: pp. 209-219. doi:10.31399/asm.hb.v24.a0006621.

[7] T. DebRoy, H.L. Wei, J.S. Zuback, T. Mukherjee, J.W. Elmer, J.O. Milewski, A.M. Beese, A. Wilson-Heid, A. De, W. Zhang, Additive manufacturing of metallic components - Process, structure and properties, Prog. Mater. Sci. 92 (2018) 112-224. doi:10.1016/j.pmatsci.2017.10.001.

[8] P.A. Lykov, E.V. Safonov, A.M. Akhmedianov, Selective Laser Melting of Copper, Mater. Sci. Forum. 843 (2016) 284-288. doi:10.4028/www.scientific.net/MSF.843.284.

[9] L.B. Benedetti, C.H. Ahrens, Study on selective laser melting of copper, in: $9^{\circ}$ Congr. Bras. Eng. Fabr., ABCM, Joinville, Santa Catarina, Brasil, 2017: pp. 1-10.

[10] F. Trevisan, C. Flaviana, M. Diego, F. Paolo, Selective laser melting of chemical pure copper powders, in: Euro PM2017, 2017: pp. 1-6. doi:10.1097/00000433-198206000-00020.

[11] C. Silbernagel, L. Gargalis, I. Ashcroft, R. Hague, M. Galea, P. Dickens, Electrical resistivity of pure copper processed by medium-powered laser powder bed fusion additive manufacturing for use in electromagnetic applications, Addit. Manuf. $29 \quad$ (2019) 100831. doi:10.1016/j.addma.2019.100831.

[12] M. Sinico, G. Cogo, M. Benettoni, I. Calliari, A. Pepato, Influence of powder particle size distribution on the printability of pure copper for selective laser melting, in: 30th Annu. Int. Solid Free. Fabr. Symp., Solid Freeform Fabrication, Austin, Texas, USA, 2019: pp. 1-11.

[13] L. Constantin, Z. Wu, N. Li, L. Fan, J.-F. Silvain, Y.F. Lu, Laser 3D printing of Complex Copper Structures, Addit. Manuf. (2020) 101268. doi:10.1016/j.addma.2020.101268.

[14] T.-T. Ikeshoji, K. Nakamura, M. Yonehara, K. Imai, H. Kyogoku, Selective Laser Melting of Pure Copper, JOM. 70 (2018) 396-400. doi:10.1007/s11837-017-2695-x.

[15] M. Colopi, A.G. Demir, L. Caprio, B. Previtali, Limits and solutions in processing pure Cu via selective laser melting using a high-power single-mode fiber laser, Int. J. Adv. Manuf. Technol. 104 (2019) 2473-2486. doi:10.1007/s00170-019-04015-3.

[16] S.D. Jadhav, S. Dadbakhsh, L. Goossens, J.-P. Kruth, J. Van Humbeeck, K. Vanmeensel, Influence of selective laser melting process parameters on texture evolution in pure copper, J. Mater. Process. Technol. 270 (2019) 47-58. doi:10.1016/j.jmatprotec.2019.02.022. 
[17] M. Naeem, Laser Processing of Reflective Materials, Laser Tech. J. 10 (2013) 18-20. doi:10.1002/latj.201390001.

[18] S. Buls, A Smart Machine for Selective Laser Melting, Ph.D. thesis, KU Leuven, 2018. https://www.kuleuven.be/doctoraatsverdediging/fiches/3E11/3E110496.htm.

[19] S.J. Raab, R. Guschlbauer, M.A. Lodes, C. Körner, Thermal and Electrical Conductivity of 99.9\% Pure Copper Processed via Selective Electron Beam Melting, Adv. Eng. Mater. 18 (2016) 1661-1666. doi:10.1002/adem.201600078.

[20] R. Fabbro, M. Dal, P. Peyre, F. Coste, M. Schneider, V. Gunenthiram, Analysis and possible estimation of keyhole depths evolution, using laser operating parameters and material properties, J. Laser Appl. 30 (2018) 032410. doi:10.2351/1.5040624.

[21] R. Fabbro, Scaling laws for the laser welding process in keyhole mode, J. Mater. Process. Technol. 264 (2019) 346-351. doi:10.1016/j.jmatprotec.2018.09.027.

[22] K.C. Mills, Cu Pure Copper, in: Recomm. Values Thermophys. Prop. Sel. Commer. Alloy., Elsevier, 2002: pp. 89-97. doi:10.1533/9781845690144.89.

[23] G. Jing, W. Huang, H. Yang, Z. Wang, Microstructural evolution and mechanical properties of $300 \mathrm{M}$ steel produced by low and high power selective laser melting, J. Mater. Sci. Technol. 48 (2020) 44-56. doi:10.1016/j.jmst.2019.12.020.

[24] B. Jackson, R. Torrens, L. Bolzoni, F. Yang, M. Fry, A. Mukhtar, Additive Manufacturing of Ti-6Al-4V with Added Boron: Microstructure and Hardness Modification, Key Eng. Mater. 770 (2018) 165-173. doi:10.4028/www.scientific.net/KEM.770.165.

[25] X. Yan, C. Chang, D. Dong, S. Gao, W. Ma, M. Liu, H. Liao, S. Yin, Microstructure and mechanical properties of pure copper manufactured by selective laser melting, Mater. Sci. Eng. A. 789 (2020) 139615. doi:10.1016/j.msea.2020.139615.

[26] J. Huang, X. Yan, C. Chang, Y. Xie, W. Ma, R. Huang, R. Zhao, S. Li, M. Liu, H. Liao, Pure copper components fabricated by cold spray (CS) and selective laser melting (SLM) technology, Surf. Coatings Technol. 395 (2020) 125936. doi:10.1016/j.surfcoat.2020.125936.

[27] S.D. Jadhav, J. Vleugels, J. Kruth, J. Van Humbeeck, K. Vanmeensel, Mechanical and electrical properties of selective laser-melted parts produced from surface-oxidized copper powder, Mater. Des. Process. Commun. 2 (2020) 1-8. doi:10.1002/mdp2.94.

[28] R. Guschlbauer, S. Momeni, F. Osmanlic, C. Körner, Process development of $99.95 \%$ pure copper processed via selective electron beam melting and its mechanical and physical properties, Mater. Charact. 143 (2018) 163-170. doi:10.1016/j.matchar.2018.04.009.

[29] Aurubis, Technical data sheet - $\mathrm{C} 10200 \quad(\mathrm{Cu}-\mathrm{OF} \quad), 2018$. https://www.aurubis.com/binaries/content/assets/aurubisrelaunch/files/datenblatter/cuof/c10200-cu-of-us.pdf.

[30] J.R. Davis, Associates, ASM Specialty Handbook® - Copper and Copper Alloys, ASM International, https://www.asminternational.org/documents/10192/1849770/ACFAA67.pdf.

[31] D. Champman, High conductivity copper for electrical engineering, 2016.

[32] R.N. Caron, Copper: Alloying, in: Encycl. Mater. Sci. Technol., Elsevier, 2001: pp. 1652-1660. doi:10.1016/B0-08-043152-6/00289-8.

[33] A. Yegyan Kumar, J. Wang, Y. Bai, S.T. Huxtable, C.B. Williams, Impacts of process-induced porosity on material properties of copper made by binder jetting additive manufacturing, Mater. Des. 182 (2019) 108001. doi:10.1016/j.matdes.2019.108001. 
[34] Y. Zhou, X. Zeng, Z. Yang, H. Wu, Effect of crystallographic textures on thermal anisotropy of selective laser melted Cu-2.4Ni-0.7Si alloy, J. Alloys Compd. 743 (2018) 258-261. doi:10.1016/j.jallcom.2018.01.335.

[35] S.F. Abbas, S.-J. Seo, K.-T. Park, B.-S. Kim, T.-S. Kim, Effect of grain size on the electrical conductivity of copper-iron alloys, J. Alloys Compd. 720 (2017) 8-16. doi:10.1016/j.jallcom.2017.05.244.

[36] Q.L. Xia, G. Chen, L. Zheng, L. Pan, Explore the feasibility of fabricating pure copper parts with low-laser energy by selective laser melting, Mater. Res. Express. (2020). doi:10.1088/20531591/abbd08.

[37] W.E. King, H.D. Barth, V.M. Castillo, G.F. Gallegos, J.W. Gibbs, D.E. Hahn, C. Kamath, A.M. Rubenchik, Observation of keyhole-mode laser melting in laser powder-bed fusion additive manufacturing, J. Mater. Process. Technol. 214 (2014) 2915-2925. doi:10.1016/j.jmatprotec.2014.06.005.

[38] I. Miyamoto, G.A. Knorovsky, Laser microwelding, in: Y. Zhou (Ed.), Microjoining and Nanojoining, Elsevier, 2008: pp. 345-417. doi:10.1533/9781845694043.2.345.

[39] L.G. Pittaway, The temperature distributions in thin foil and semi-infinite targets bombarded by an electron beam, Br. J. Appl. Phys. 15 (1964) 967-982. doi:10.1088/0508-3443/15/8/314.

[40] A. Hess, R. Schuster, A. Heider, R. Weber, T. Graf, Continuous Wave Laser Welding of Copper with Combined Beams at Wavelengths of 1030nm and of 515nm, Phys. Procedia. 12 (2011) 8894. doi:10.1016/j.phpro.2011.03.012.

[41] R. Fabbro, Depth Dependence and Keyhole Stability at Threshold, for Different Laser Welding Regimes, Appl. Sci. 10 (2020) 1487. doi:10.3390/app10041487.

[42] J. Trapp, A.M. Rubenchik, G. Guss, M.J. Matthews, In situ absorptivity measurements of metallic powders during laser powder-bed fusion additive manufacturing, Appl. Mater. Today. 9 (2017) 341-349. doi:10.1016/j.apmt.2017.08.006.

[43] A. Blom, P. Dunias, P. van Engen, W. Hoving, J. de Kramer, Process spread reduction of laser microspot welding of thin copper parts using real-time control, in: A. Pique, K. Sugioka, P.R. Herman, J. Fieret, F.G. Bachmann, J.J. Dubowski, W. Hoving, K. Washio, D.B. Geohegan, F. Traeger, K. Murakami (Eds.), 2003: p. 493. doi:10.1117/12.478612.

[44] A.M. Prokhorov, I.N. Mihailescu, I. Ursu, V.I. Konov, Laser heating of metals, CRC Press, Bristol; Philadelphia, 1990.

[45] L.-J. Zhang, G.-F. Zhang, J. Ning, X.-J. Zhang, J.-X. Zhang, Microstructure and properties of the laser butt welded 1.5-mm thick T2 copper joint achieved at high welding speed, Mater. Des. 88 (2015) 720-736. doi:10.1016/j.matdes.2015.09.072.

[46] M. Bayat, A. Thanki, S. Mohanty, A. Witvrouw, S. Yang, J. Thorborg, N.S. Tiedje, J.H. Hattel, Keyhole-induced porosities in Laser-based Powder Bed Fusion (L-PBF) of Ti6Al4V: Highfidelity modelling and experimental validation, Addit. Manuf. 30 (2019) 100835. doi:10.1016/j.addma.2019.100835.

[47] R. Cunningham, C. Zhao, N. Parab, C. Kantzos, J. Pauza, K. Fezzaa, T. Sun, A.D. Rollett, Keyhole threshold and morphology in laser melting revealed by ultrahigh-speed $\mathrm{x}$-ray imaging, Science (80-. ). 363 (2019) 849-852. doi:10.1126/science.aav4687.

[48] S.A. Khairallah, A.T. Anderson, A. Rubenchik, W.E. King, Laser powder-bed fusion additive manufacturing: Physics of complex melt flow and formation mechanisms of pores, spatter, and denudation zones, Acta Mater. 108 (2016) 36-45. doi:10.1016/j.actamat.2016.02.014.

[49] Y. Chen, S.J. Clark, C.L.A. Leung, L. Sinclair, S. Marussi, M.P. Olbinado, E. Boller, A. Rack, 
I. Todd, P.D. Lee, In-situ Synchrotron imaging of keyhole mode multi-layer laser powder bed fusion additive manufacturing, Appl. Mater. Today. $20 \quad$ (2020) 100650. doi:10.1016/j.apmt.2020.100650.

[50] S.D. Jadhav, D. Fu, M. Deprez, K. Ramharter, D. Willems, B. Van Hooreweder, K. Vanmeensel, Highly conductive and strong $\mathrm{CuSn} 0.3$ alloy processed via laser powder bed fusion starting from a tin-coated copper powder, Addit. Manuf. $36 \quad$ (2020) 101607. doi:10.1016/j.addma.2020.101607.

[51] S.D. Jadhav, P.P. Dhekne, S. Dadbakhsh, J.-P. Kruth, J. Van Humbeeck, K. Vanmeensel, Surface Modified Copper Alloy Powder for Reliable Laser-based Additive Manufacturing, Addit. Manuf. 35 (2020) 101418 (1-13). doi:10.1016/j.addma.2020.101418.

[52] S.D. Jadhav, P.P. Dhekne, E. Brodu, B. Van Hooreweder, S. Dadbakhsh, J.-P. Kruth, J. Van Humbeeck, K. Vanmeensel, Laser powder bed fusion additive manufacturing of highly conductive parts made of optically absorptive carburized CuCr1 powder, Mater. Des. 198 (2021) 109369. doi:10.1016/j.matdes.2020.109369.

[53] V. Lindström, O. Liashenko, K. Zweiacker, S. Derevianko, V. Morozovych, Y. Lyashenko, C. Leinenbach, Laser Powder Bed Fusion of Metal Coated Copper Powders, Materials (Basel). 13 (2020) 3493. doi:10.3390/ma13163493.

[54] M. Balbaa, S. Mekhiel, M. Elbestawi, J. McIsaac, On selective laser melting of Inconel 718: Densification, surface roughness, and residual stresses, Mater. Des. 193 (2020) 108818. doi:10.1016/j.matdes.2020.108818.

[55] S.D. Jadhav, S. Dadbakhsh, R. Chen, R. Shabadi, J. Kruth, J. Van Humbeeck, K. Vanmeensel, Modification of Electrical and Mechanical Properties of Selective Laser-Melted CuCr0.3 Alloy Using Carbon Nanoparticles, Adv. Eng. Mater. 22 (2020) 1900946 (1-14). doi:10.1002/adem.201900946.

[56] A.B. Spierings, M. Schneider, R. Eggenberger, Comparison of density measurement techniques for additive manufactured metallic parts, Rapid Prototyp. J. 17 (2011) 380-386. doi:10.1108/13552541111156504. 


\section{Supplementary Figures}

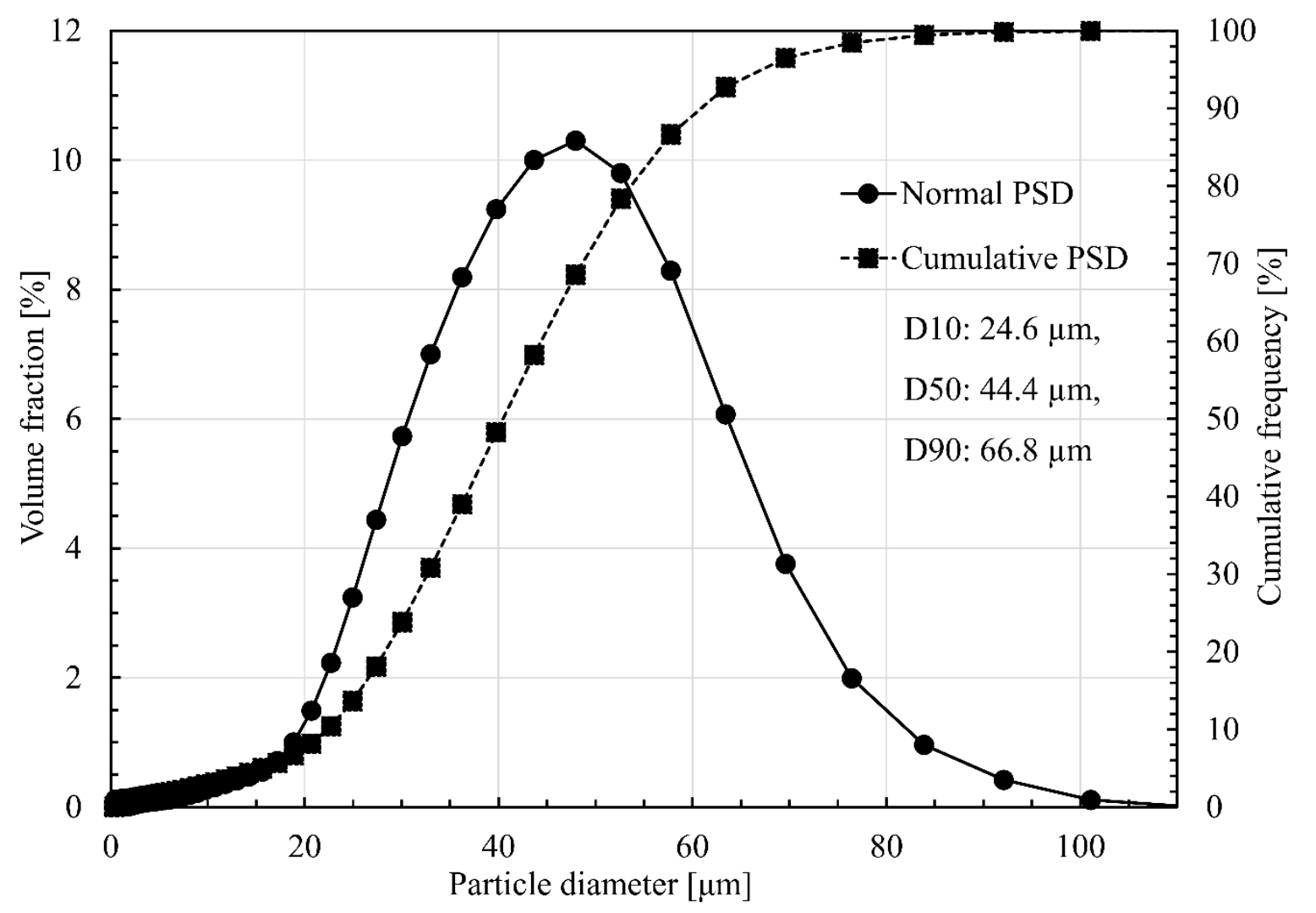

Supplementary Figure 1: Particle size distribution (PSD) of the starting pure copper powder. 

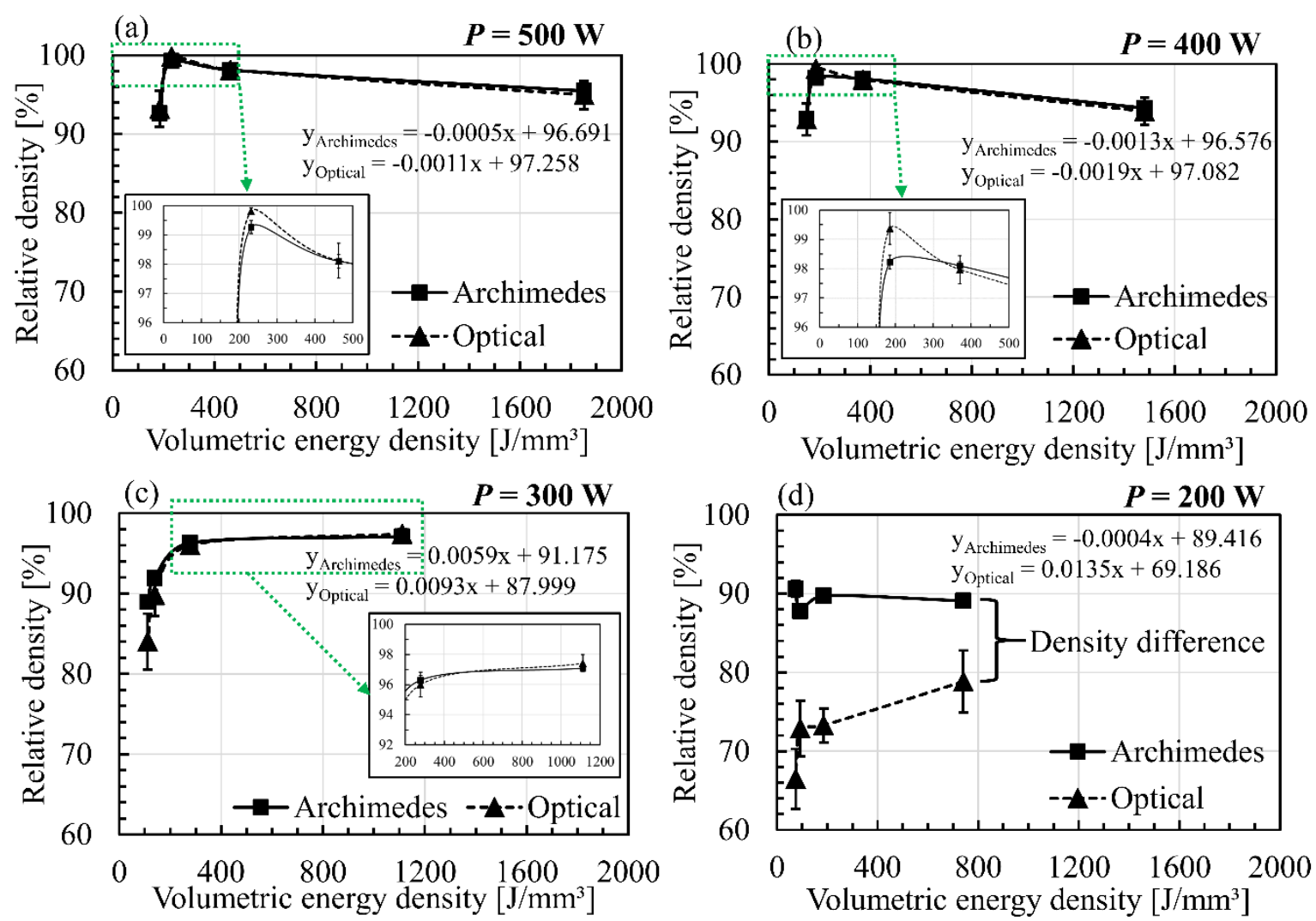

Supplementary Figure 2: The relative density of pure copper parts measured via both the Archimedes and optical methods are shown as a function of the volumetric energy density for (a) $500 \mathrm{~W}$, (b) 400 $\mathrm{W}$, (c) $300 \mathrm{~W}$, and (d) $200 \mathrm{~W}$ laser power levels. The equations corresponding to linear fit trend lines are provided for reference. As seen, for laser power levels of 300, 400, and $500 \mathrm{~W}$, the density measurement curves of the Archimedes and optical methods are globally in a rather good agreement; however, a closer view at the highest density parts, as shown in the respective insets, indicates that the density values measured by the optical method are slightly higher compared to the Archimedes density of the same parts. On the other hand, at $200 \mathrm{~W}$ laser power, the density values measured by the optical method are substantially lower than the Archimedes method, and a density difference is visible for the same parts measured via two different techniques, as shown in Figure (d). The slightly higher estimation of the relative density for the highest density parts via optical method could be attributed to the measurement methodology of the optical density measurements, which does not cover the entire volume of the sample; rather, it is measured on a $5.4 \times 5.4 \mathrm{~mm}^{2}$ area on at least three cross-sectional planes of an individual sample. On the other hand, the lower estimation of the density values for the low-density parts via the optical method, or in other words, the higher estimation of density values via the Archimedes method, could be attributed to the presence of open porosity. During the Archimedes measurement, the presence of open porosity allows the liquid-medium (i.e., ethanol in the present study) to penetrate into the sample, leading to a lowering of the sample-volume. Since the sample-volume considered for the Archimedes density calculation is lower than the real volume of the sample (for samples with open porosity), the density values measured by the Archimedes method are overestimated. Consequently, for the highest density parts ( $P 300 \mathrm{~W}, P 400$ $\mathrm{W}$, and $P 500 \mathrm{~W}$ ), the density values measured via the Archimedes method should be referred to, whereas for the low-density parts $(P 200 \mathrm{~W})$, the density values measured via the optical method are more reliable. For more details on the density measurements and their traits, the reader is referred to 'A.B. Spierings, M. Schneider, R. Eggenberger, Comparison of density measurement techniques for additive manufactured metallic parts, Rapid Prototyp. J. 17 (2011) 380-386. doi:10.1108/13552541111156504.' 

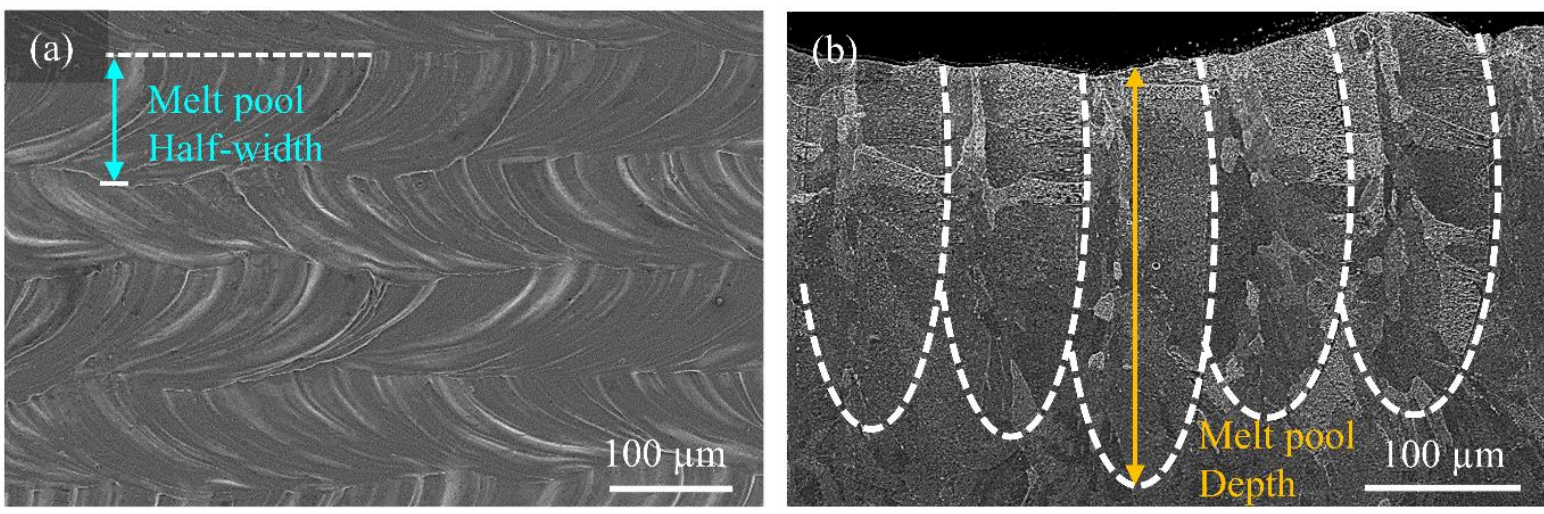

Supplementary Figure 3: SEM image showing (a) top surface (as-built condition) and (b) crosssectional surface (after chemical etching) of a typical L-PBF fabricated pure copper part. The melt pool widths were evaluated on the top surface from the melt pool half-width measurements as illustrated in Figure (a), while the melt pool depths were measured on the cross-sectional surface as demonstrated in Figure (b).

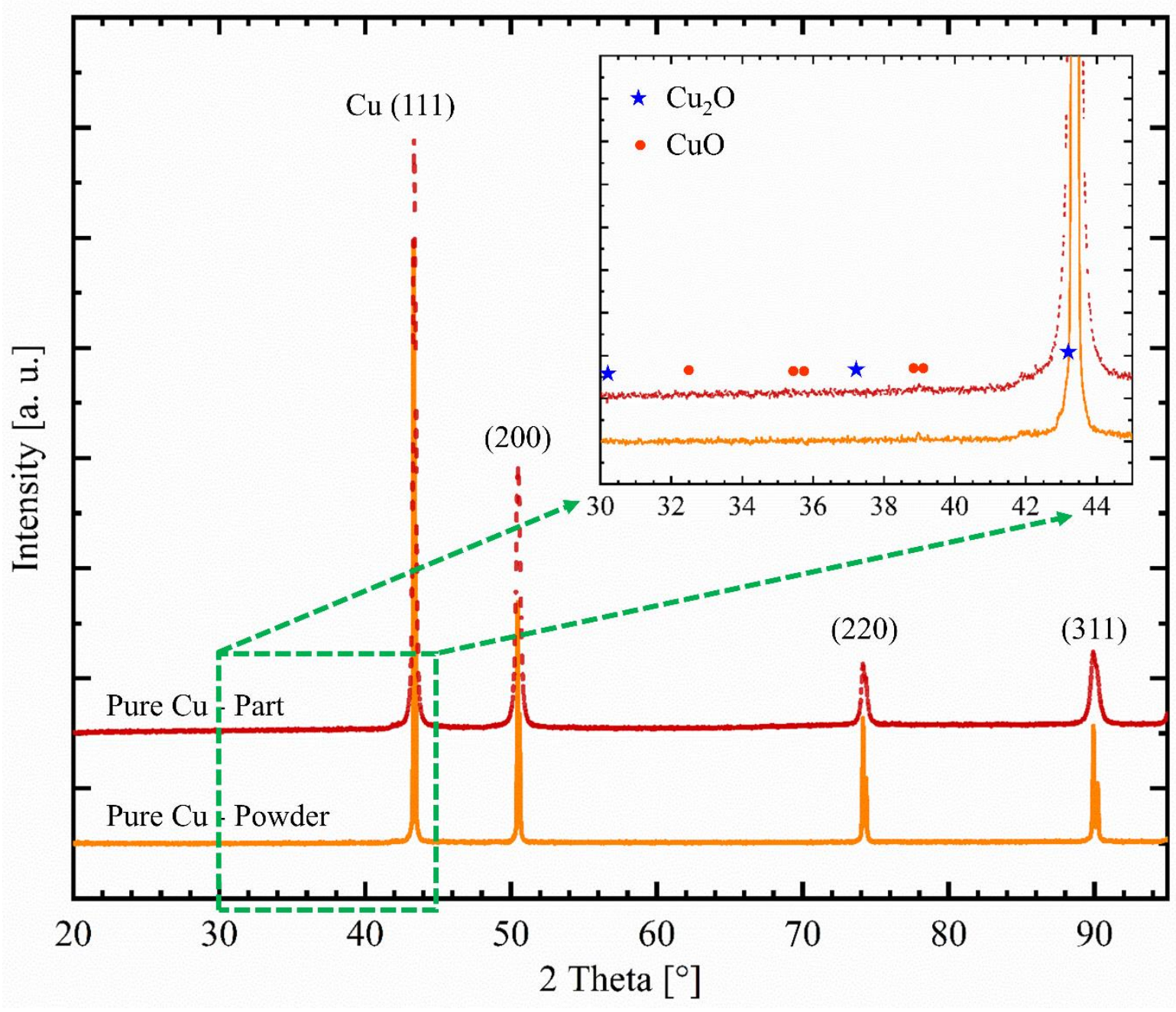

Supplementary Figure 4: X-ray diffraction (XRD) spectra of pure copper powder and the corresponding L-PBF fabricated pure copper part measured within a $20-95^{\circ} 2 \theta$ range. As seen, the peaks corresponding to pure copper are identified by the corresponding miller indices. However, the peaks corresponding to $\mathrm{Cu}_{2} \mathrm{O}$ and $\mathrm{CuO}$ are not detected, indicating the presence of a single-phase alpha copper (FCC) structure. 